\title{
Modelled radiative forcing of the direct aerosol effect with multi-observation evaluation
}

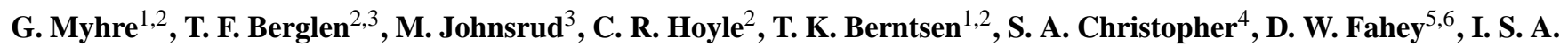

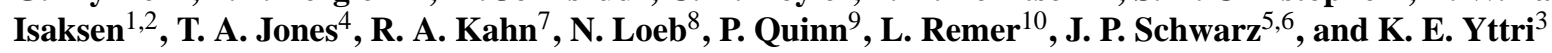 \\ ${ }^{1}$ Center for International Climate and Environmental Research-Oslo, Oslo, Norway \\ ${ }^{2}$ Department of Geosciences, University of Oslo, Oslo, Norway \\ ${ }^{3}$ Norwegian Institute for Air Research (NILU), Kjeller, Norway \\ ${ }^{4}$ Department of Atmospheric Science, The University of Alabama in Huntsville, Huntsville, Alabama, USA \\ ${ }^{5}$ Chemical Sciences Division, Earth System Research Laboratory, NOAA, Boulder, CO, USA \\ ${ }^{6}$ Cooperative Institute for Research in Environmental Sciences, University of Colorado, Boulder, CO, USA \\ ${ }^{7}$ Laboratory for Atmospheres, NASA Goddard Space Flight Center, Greenbelt, Maryland, USA \\ ${ }^{8}$ NASA Langley Atmospheric Research Center (LaRC), Hampton, Virginia, USA \\ ${ }^{9}$ NOAA PMEL, Seattle, USA \\ ${ }^{10}$ Laboratory for Atmospheres, NASA Goddard Space Flight Center (GSFC), Greenbelt, Maryland, USA
}

Received: 2 June 2008 - Published in Atmos. Chem. Phys. Discuss.: 7 July 2008

Revised: 6 January 2009 - Accepted: 2 February 2009 - Published: 19 February 2009

\begin{abstract}
A high-resolution global aerosol model (Oslo CTM2) driven by meteorological data and allowing a comparison with a variety of aerosol observations is used to simulate radiative forcing $(\mathrm{RF})$ of the direct aerosol effect. The model simulates all main aerosol components, including several secondary components such as nitrate and secondary organic carbon. The model reproduces the main chemical composition and size features observed during large aerosol campaigns. Although the chemical composition compares best with ground-based measurement over land for modelled sulphate, no systematic differences are found for other compounds. The modelled aerosol optical depth (AOD) is compared to remote sensed data from AERONET ground and MODIS and MISR satellite retrievals. To gain confidence in the aerosol modelling, we have tested its ability to reproduce daily variability in the aerosol content, and this is performing well in many regions; however, we also identified some locations where model improvements are needed. The annual mean regional pattern of AOD from the aerosol model is broadly similar to the AERONET and the satellite retrievals (mostly within 10-20\%). We notice a significant improvement from MODIS Collection 4 to Collection 5 compared to AERONET data. Satellite derived estimates of aerosol radiative effect over ocean for clear sky conditions differs significantly on regional scales (almost up to a fac-
\end{abstract}

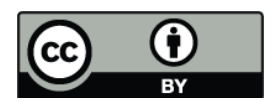

Correspondence to: G. Myhre (gunnar.myhre@ cicero.uio.no) tor two), but also in the global mean. The Oslo CTM2 has an aerosol radiative effect close to the mean of the satellite derived estimates. We derive a radiative forcing $(\mathrm{RF})$ of the direct aerosol effect of $-0.35 \mathrm{Wm}^{-2}$ in our base case. Implementation of a simple approach to consider internal black carbon (BC) mixture results in a total RF of $-0.28 \mathrm{Wm}^{-2}$. Our results highlight the importance of carbonaceous particles, producing stronger individual RF than considered in the recent IPCC estimate; however, net RF is less different. A significant RF from secondary organic aerosols (SOA) is estimated (close to $-0.1 \mathrm{Wm}^{-2}$ ). The SOA also contributes to a strong domination of secondary aerosol species for the aerosol composition over land. A combination of sensitivity simulations and model evaluation show that the RF is rather robust and unlikely to be much stronger than in our best estimate.

\section{Introduction}

It is now well documented that atmospheric aerosols strongly impact the Earth's radiation balance and climate through the direct scattering and absorption of solar radiation and through their influence on clouds (Forster et al., 2007; Kaufman et al., 2002; Ramanathan et al., 2001a). Schulz et al. (2006) found large differences (even in the sign) in the direct aerosol radiative forcing (RF) between nine models in a global model intercomparison exercise with identical

Published by Copernicus Publications on behalf of the European Geosciences Union. 
emissions of aerosols and their precursors. Studies based on observational data show an even stronger negative direct aerosol RF than that calculated by the models (Bellouin et al., 2005; Chung et al., 2005). To better quantify the direct aerosol effect and to quantify its uncertainty there is a need to further evaluate the global aerosol models and to investigate those parts of the RF calculation due to the direct aerosol effect.

Figure 1 shows that many factors influence the RF due to the direct aerosol effect. The aerosol chemical composition and size distribution are the main factors for determining the aerosol optical properties. The aerosol chemical composition is complex and includes carbonaceous matter, primary wind driven components such as sea salt and mineral dust, as well as secondary components such as sulphate and nitrate. Black carbon (BC) is a primary emitted species whereas organic carbon (OC) can be emitted directly to the atmosphere, or result from secondary formation. OC consists of a variety of chemical constituents and the processes leading to the formation of all constituents are still not well resolved (Andreae and Gelencser, 2006; Fuzzi et al., 2006; Graber and Rudich, 2006; Kanakidou et al., 2005; Robinson et al., 2007). Of the aerosol optical properties, it is especially aerosol optical depth (AOD) and single scattering albedo that are of importance, but the asymmetry factor is also significant. The single scattering albedo is vital, since local and global RF can change substantially with this quantity (Hansen et al., 1997; Haywood and Shine, 1995). BC is the main cause for complicating the derivation of the single scattering albedo (Bond and Bergstrom, 2006; Bond et al., 2006; Fuller et al., 1999) but there are also indications that some of the OC is absorbing solar radiation (Andreae and Gelencser, 2006; Lukacs et al., 2007). Relative humidity plays a crucial role in determining the aerosol optical properties, through swelling of hygroscopic particles (Haywood et al., 1997; Myhre et al., 2002, 2004). A likely major reason for the large difference in the modelling of the direct aerosol effect is the vertical profile of the aerosols (Schulz et al., 2006) where the model differences are large (Textor et al., 2006). In addition, surface albedo and clouds are important factors for the radiative forcing, in particular for absorbing aerosols.

In recent years there have been considerable advances in the extent and quality of aerosol observations. Aircraft, shipboard, and ground-station measurements during field campaigns as well as long term measurements at ground stations give direct information on chemical composition, but they often have limited spatial coverage. The network of sunphotometers within AERONET (Holben et al., 1998) is essential for validation of satellite data and global aerosol models, in particular for AOD. The near global coverage of AOD through satellites has given much insight into the aerosol distribution. Forster et al. (2007) provided an overview of available satellite retrievals of aerosols and the data that can be provided for aerosol studies. The direct radiative effect of aerosols over the oceans is important information for the val-

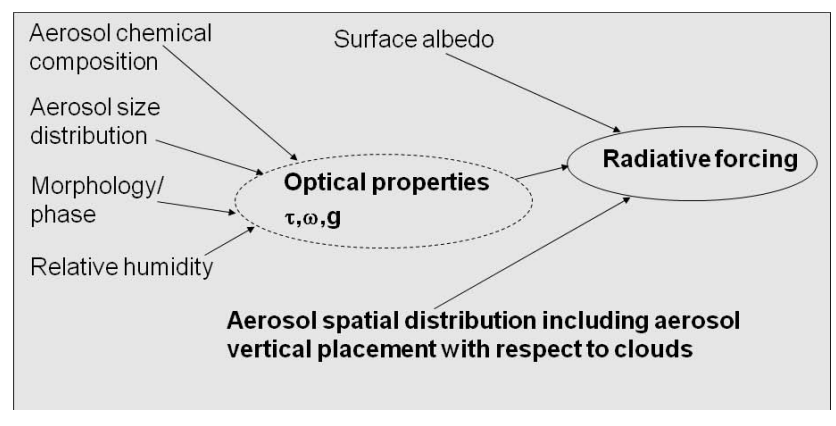

Fig. 1. Illustrative of main factors influencing the RF of the direct aerosol effect. Aerosol optical depth $(\tau)$, single scattering albedo $(\omega)$, and asymmetry factor $(\mathrm{g})$ are the optical properties.

idation of global aerosols models (Yu et al., 2006). LIDAR instruments at ground-based stations or on aircraft, ships and satellite platforms can give vertical aerosol information. This type of data can elsewhere only be provided by aircraft data from field campaigns or stereo imaging near major aerosol sources (Kahn et al., 2007b). The measurements above provide aerosol information directly, but information from radiation measurements may also be considered but then aerosol information is not directly available. Surface solar radiation measurements show substantial change in since 1950 (Alpert et al., 2005; Liepert, 2002; Stanhill and Cohen, 2001; Wild et al., 2005). However, this is not solely linked to atmospheric aerosols, since gases and contrails also contribute, although aerosols are a major factor (Kvalevåg and Myhre, 2007).

In this paper we will estimate the RF due to the direct aerosol effect and evaluate its uncertainty with a relatively high resolution global aerosol model (Oslo CTM2) with all the main aerosol components included. We will use information from large aerosol field campaigns and long term surface measurements to evaluate the performance of the model with respect chemical composition. For AOD, a comparison with satellite and AERONET data will be performed. To gain confidence in the model results, we investigate whether the model is able to reproduce observed daily variations. Analysis of the agreement between the model and AERONET data for the single scattering albedo and the asymmetry factor will also be performed. Several global aerosol models underestimate the radiative effect of aerosols over ocean compared to satellite data (Yu et al., 2006), and here we make a comparison with several of these data sets. The uncertainty analysis is performed based on the level of disagreement between model results and observations. The model evaluation is described in Sect. 3, after a brief model description in Sect. 2. The simulation of RF of the direct aerosol effect and its uncertainty are described in Sect. 4. 


\section{Model description}

The Oslo CTM2 is an off-line global aerosol-chemistry transport model driven with meteorological data from the ECMWF (Berglen et al., 2004). The meteorological data have been generated by running the Integrated Forecast System (IFS) model at the ECMWF with output at a three hour time resolution. The Oslo CTM2 can be run at various spatial resolutions and in the present study the simulations are performed in $1 \times 1$ degree resolution and 40 vertical layers. The simulations are performed using meteorological data for year 2004. The Oslo CTM2 has been compared to observations and other global aerosol models (Kinne et al., 2006; Myhre et al., 2007; Schulz et al., 2006; Textor et al., 2006). Mineral dust (Grini et al., 2005), sea salt (Grini et al., 2002), sulphate (Berglen et al., 2004), and carbonaceous aerosols (Berntsen et al., 2006; Myhre et al., 2003a) have been included in the previous studies cited above. Nitrate (Myhre et al., 2006) based on (Metzger et al., 2002) and secondary organic aerosols (SOA) (Hoyle et al., 2007) have also recently been implemented. For both of these species, interaction between the aerosol components and a detailed chemistry scheme are taken into account. Nitrate can exit as fine mode ammonium nitrate. In addition, nitric acid can react with sea salt to form sodium nitrate, primarily in coarse mode particles. For SOA, organics can partition into existing organic aerosol as well as sulphate aerosols (Hoyle et al., 2007). Unlike the other aerosol species, SOA have been calculated with a spatial resolution of T42 (2.8 degrees) and interpolated to a $1 \times 1$ degree grid, as the computational cost of running the SOA scheme in a $1 \times 1$ resolution is too high.

The radiative forcing of the direct aerosol effect for anthropogenic aerosol compounds has been provided within the AeroCom initiative (Schulz et al., 2006). Some changes in the model have been included since then, i.e. longer conversion time from hydrophobic to hydrophilic carbonaceous aerosol, based on recent measurements, has been implemented (Maria et al., 2004). An organic mass (OM)/OC ratio of 2.6 have been used for emissions from biomass burning (Formenti et al., 2003) whereas a factor of 1.6 was applied for emissions from combustion of fossil fuel (Polidori et al., 2008; Turpin and Lim, 2001). Emissions of aerosol species and their precursors are as in (Myhre et al., 2007; Schulz et al., 2006) except that $\mathrm{SO}_{2}$ emissions over Europe have been updated with values for 2004 from EMEP (Vestreng et al., 2007) and carbonaceous aerosols from biomass burning for the year 2004 from Global Fire Emission Database version 2 (GFEDv2) (van der Werf et al., 2006).

Aerosol optical properties (including the size distributions) and radiative forcing calculations are as described in (Myhre et al., 2007), except for aerosol from biomass burning. The single scattering albedo of aerosols from biomass burning is modelled based on the hydrophobic and hydrophilic carbonaceous particles. The single scattering albedo for new particles (hydrophobic) is reduced by 0.25 and scaled with the $\mathrm{BC}$ content. Water uptake by the hydrophilic organic carbon aerosols is taken into account (Magi and Hobbs, 2003). The single scattering albedo of biomass burning aerosols is now more in line with recent measurements from DABEX (Haywood, 2008; Johnson et al., 2008) with values slightly above 0.8 .

\section{Model evaluation}

\subsection{Chemical composition}

\subsubsection{Chemical composition from surface data networks}

In this section we compare the model surface chemical composition with data provided by surface data networks. The three networks EMEP, IMPROVE, and EANET in Europe, USA, and Asia, respectively are used and the comparison in this study is restricted to annual mean data for 2004 (with exceptions for carbonaceous aerosols from EMEP). The five chemical species included in this analysis are sulphate, nitrate, ammonium, BC, and OC. The modelled sulphate concentration compares well with that of the three surface observation networks (see Fig. 2). For IMPROVE, an excellent agreement is found except for some of the stations with low sulphate concentrations. The observations of nitrate in the IMPROVE data set are for fine mode particles, whereas for EMEP and EANET the observations represent sizes up to around $10 \mu \mathrm{m}$. In the model we have included fine and coarse mode nitrate in the comparison for EMEP and EANET, whereas for comparison with IMPROVE we include $15 \%$ of the coarse mode (a typical value of the coarse mode that has a diameter less than $2.5 \mu \mathrm{m}$ ) in addition to the fine mode nitrate. For nitrate, the agreement is not as good as for sulphate. For IMPROVE only a few model values are outside the factor of two difference line of the observations, but the scatter is larger than for sulphate. In EMEP and EANET, the model has a tendency to overestimate the nitrate concentration. This can be related to measurement complexity as ammonium nitrate on the aerosol filter may dissociate into gaseous nitric acid (Fagerli and Aas, 2007). The modelled sum of aerosol nitrate and nitric acid compare more precise than for aerosol nitrate for the EMEP data (the sum nitrate is not shown only the aerosol nitrate). Compared to the EMEP observations the model has four outliers for nitrate. This could partly be attributed to particularly low concentrations in 2004 compared to previous years. Nitrate is a compound that is more complicated to model compared to sulphate since other compounds such as sulphate, ammonia, sea salt must be represented and the reaction forming ammonium nitrate is temperature dependent (Jacobson, 2001; Metzger et al., 2002; Myhre et al., 2006). Modelled concentration of ammonium compares better with the measurements than nitrate for the three networks, but not as good as for sulphate. The agreement between modelled and observed 

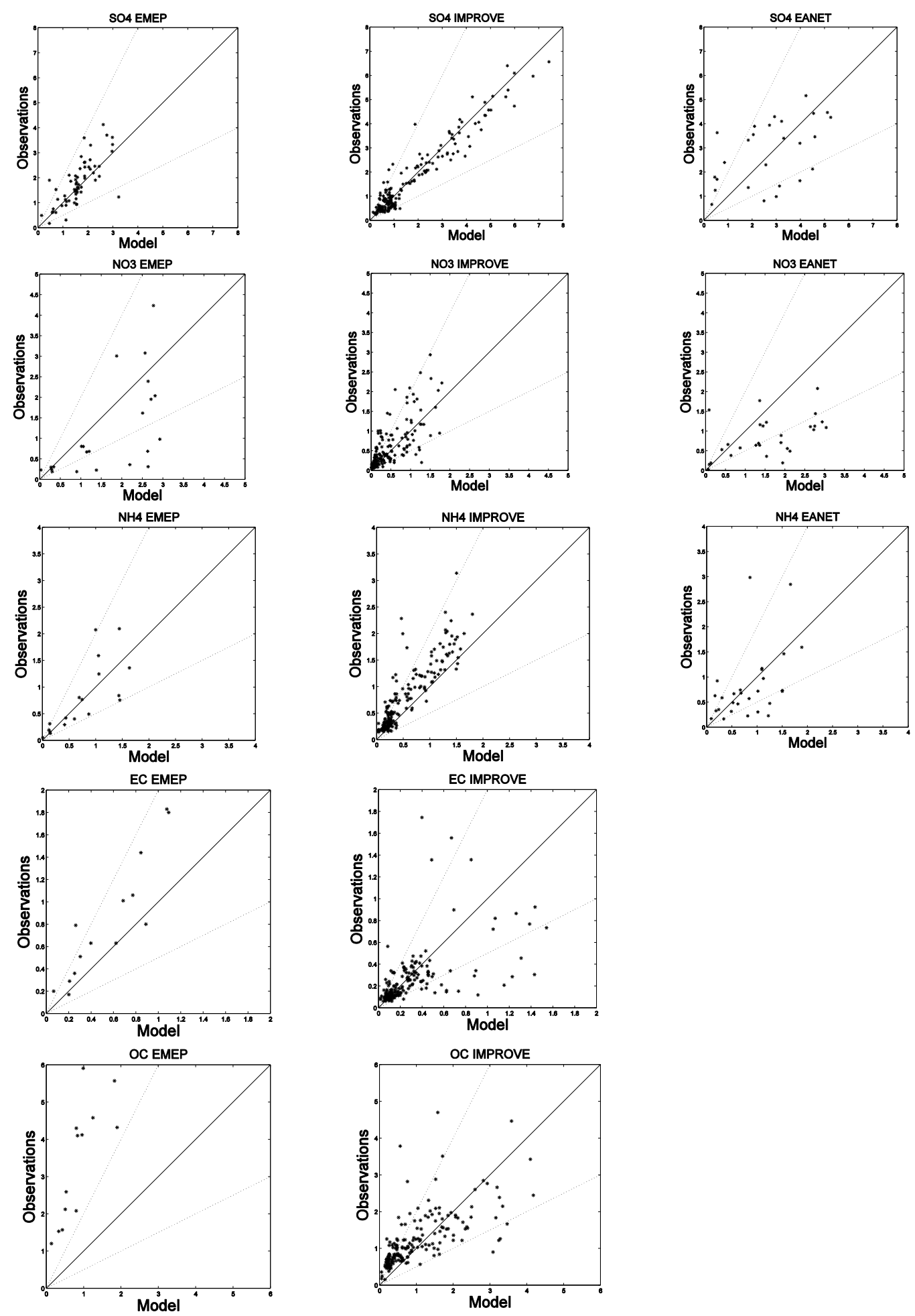

Fig. 2. Annual mean surface observations and modeled surface concentration of sulphate, nitrate, ammonium, BC, and OC from EMEP, IMPROVE, and EANET. Values given in $\mu \mathrm{g} \mathrm{m}^{-3}$. Note that a linear scale is adopted. 
concentration of ammonium is best for the IMPROVE network with a somewhat larger fraction of measurements outside the factor of two line for EMEP and EANET. Modelled $\mathrm{BC}$ concentrations are compared to observed elemental carbon (EC) measurements. Large uncertainties are associated with sampling and subsequent analysis of EC and $\mathrm{OC}$ (Gelencser, 2004). For OC this is attributed to adsorption and evaporation of semi volatile organic constituents to the filter during sampling, which can cause severe over- and underestimation of the true particulate OC loading. To separate EC and $\mathrm{OC}$ is analytically challenging, hence introducing substantial uncertainty to the observed concentrations of EC and OC. Differences between the most commonly used analytical approaches can be extensive, i.e. $>2$ for EC (Schmid et al., 2001). At most of the stations in the IMPROVE network, the model agreement is good for BC; however, for a few locations, especially those with low observed $\mathrm{BC}$ the model overestimates the BC concentration. EMEP data for carbonaceous aerosols have been collected for a campaign period from 1st of July 2002 to 1st of July 2003 (Yttri et al., 2007). Compared to these measurements the model has a small underestimation of BC. The underestimation for OC compared to the EMEP observations is much larger than for BC and for all stations the model values fell outside a factor of two differences. The modelled OC values compare well with IMPROVE data with a tendency to underestimate the observed low values and overestimate some of the medium high observed values. Without the SOA the OC concentration is strongly underestimated (about a factor of two lower than the observed). The aerosol filter samples collected during the EMEP EC/OC campaign has a cut off of $\mathrm{PM}_{10}$. Primary biological aerosol particles (PBAP), typically residing in the coarse fraction of $\mathrm{PM}_{10}$, is suggested to make a substantial contribution to some EMEP sites, in particular in Scandinavia/Northern Europe (Yttri et al., 2007). This should be noted when comparing the observed levels of OC with that of the model $\left(\mathrm{PM}_{2.5}\right)$.

\subsubsection{Chemical composition during aerosol campaigns}

Figure 3 shows measured near-surface chemical composition of fine (Fig. 3a) and coarse (Fig. 3c) from five major aerosol campaigns as compiled by Quinn and Bates (2005) (results from one campaign divided into two regions). The modelled chemical composition in the lowest model layer for fine and coarse aerosols is shown in Fig. 3b and d, respectively. The chemical composition data are obtained from different years (over the period from 1995-2002), whereas the meteorological data for the model is for the year 2004. In the model results, of the chemical composition the same location and time of the year as the measurements have been applied, although the meteorological situation is not the same. In our study we have restricted the study to the mass fraction of dry aerosols (no aerosol water). The mass fraction of aerosol water for a relative humidity of 50\% was included in the study of
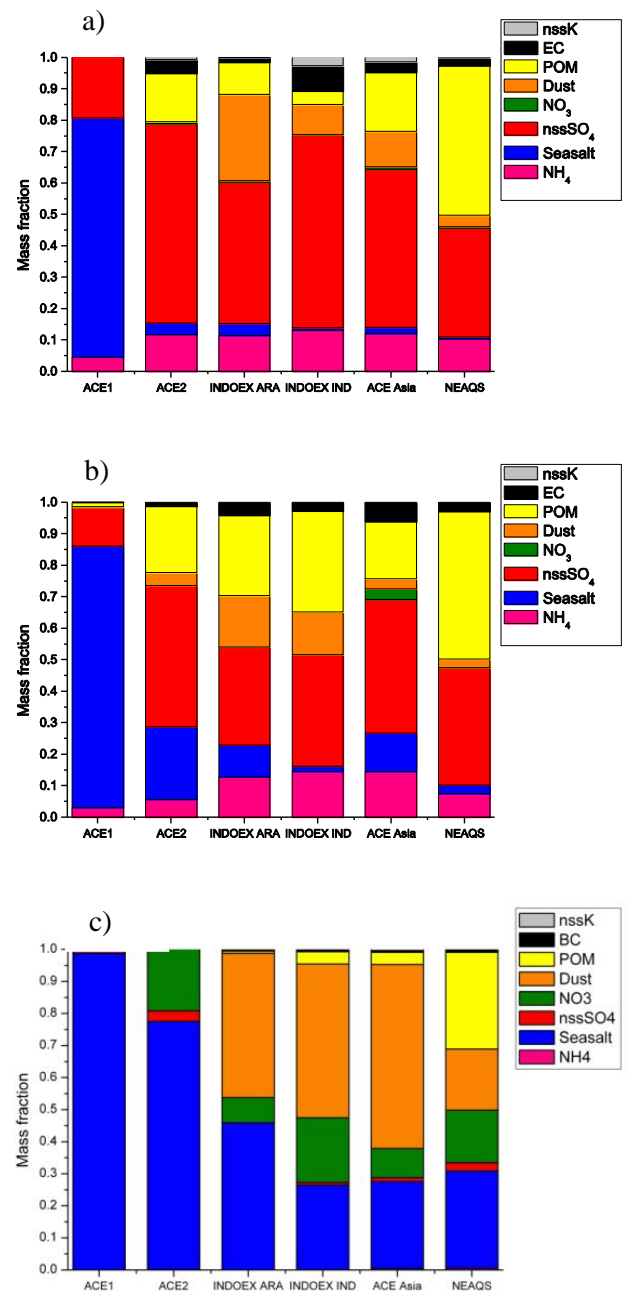

d)

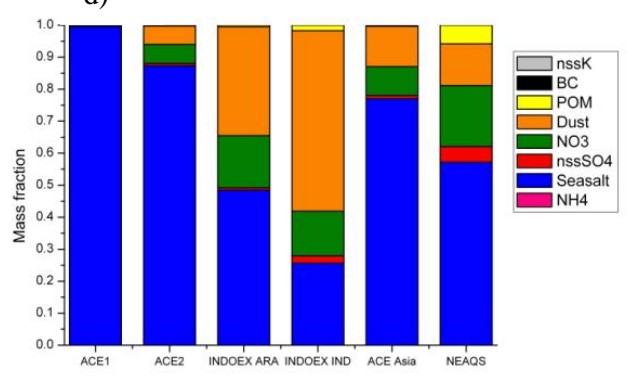

Fig. 3. Relative aerosol chemical composition of fine and coarse mode in regions of six major aerosol campaigns (a) observed fine mode (b) modeled fine mode (c) observed coarse mode (d) modeled coarse mode. Near surface concentrations are measured and model values are from the lowest level in the model. Sampling in the model is from the same location and time periods of the year as the measurements, but in the model meteorological data for 2004 is used.

Quinn and Bates (2005) based on the chemical composition and a chemical thermodynamic equilibrium model. Note that 


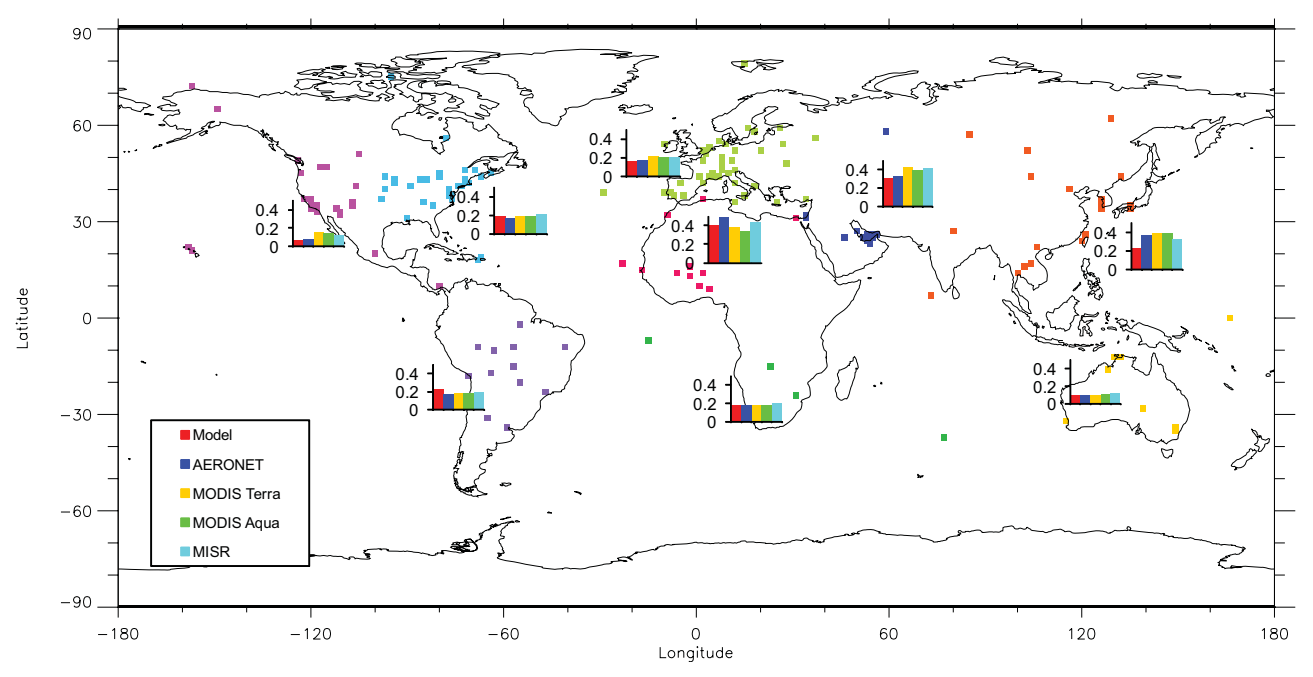

Fig. 4. Mean AOD (at $550 \mathrm{~nm}$ ) of grouped AERONET stations. AERONET stations with same colours are grouped together and the graph nearby shows the mean over the AERONET stations. Satellite data and model results are also sampled at the AERONET stations. Mean of daily data from 2004 are used in the analysis.

in some of the earliest aerosol campaigns the measurement capabilities did not allow a full quantification of the whole aerosol mass fraction (Quinn and Bates, 2005).

The model clearly reproduces the large difference in the chemical composition from the ACE1 campaign in a remote oceanic region compared to the other campaigns closer to industrial activity. Except for ACE1, the observations show an apparent dominance of aerosol components that are associated with anthropogenic aerosols. The mass fraction of ammonium in the model compares rather well with the measurements; however, with a tendency to be lower, at least for the ACE2 and NEAQS. For fine mode sea salt the mass fraction is higher in the model than in the observations, especially for ACE2 and ACE Asia. Sulphate is the dominating aerosol component in all the campaigns in the observations and the model, except for ACE1 (fine mode sea salt is dominant) and NEAQS (OM is the major fraction). Sulphate is a more dominant component in the observations than for the modelled data. This is particularly evident in ACE2 and INDOEX IND, whereas in NEAQS the modelled concentration of sulphate is higher than those observed. For ACE2, which took place in 1997, changes in the $\mathrm{SO}_{2}$ emissions over Europe can influence the results. Substantial reduction in the $\mathrm{SO}_{2}$ emission occurred in Europe in the 1990s and have even been significant until 2004 (Vestreng et al., 2007). Since mineral dust is strongly dependent on the meteorological conditions, differences between these observations and the model results are expected, but the significant mass fraction of mineral dust in the Indian Ocean can be seen in both the observations and the model. The model reproduces the observation of $\mathrm{OM}$ as the dominant aerosol species in the NEAQS region. The mass fraction of OM is similar in the model and the observations, expect during INDOEX (OM was not measured in ACE1). Compared to the other campaigns, the measurements during the INDOEX are rather sparse and are here also divided into two regions. Other measurements of chemical composition during INDOEX indicate an OM mass fraction similar to the model (Ramanathan et al., 2001b). However, these measurements are from aircraft measurements and represent other altitudes than used for the comparison in Fig. 3. Importantly, the general mass fraction of $\mathrm{BC}$ is in reasonable agreement with the measurements but for the individual campaign regions the results vary substantially. In the major campaigns over ocean which are considered here, a very small amount of nitrate in the fine mode has been measured and this is reproduced in the model. This is in contrast to observations over land where significant fine mode nitrate is observed (Crosier et al., 2007; Malm et al., 2004; Putaud et al., 2004). nss (non-sea salt) Potassium is not included in the model, but does not account for a large part of the mass fraction in the observations during the major aerosol campaigns that encountered biomass or bio-fuel burning emissions (INDOEX IND and ACE-Asia).

The chemical composition of the coarse mode differs substantially from the fine mode, and is dominated by sea salt. A striking feature in the coarse mode is the large nitrate fraction. Both the measurements and the model show that nitrate is present in the coarse mode over the ocean. This is an important result with respect to radiative forcing of nitrate aerosols as there is a large difference in radiative effect of fine and coarse mode nitrate aerosols (Myhre et al., 2006). During ACE Asia there was a large dust outbreak, which did not occur for the same time period in 2004 in the model. Thus, the dust fraction is substantially lower in the model than in the measurements for ACE Asia. The mass fraction of coarse OM is underestimated in the model when 
compared with observations. Overall, the model reproduces the observed chemical composition for the fine and coarse modes.

\subsection{Comparison with AERONET data}

For 2004 data from altogether 180 stations are available in the AERONET network of sunphotometers (Holben et al., 1998), and represent the most accurate point measurements of AOD. AERONET Level 2 and algorithm version 2 is adopted throughout this study. In addition, satellite data of AOD are compared to the AERONET data and the model results. Collection 5 data for MODIS on Terra and Aqua as well as MISR on Terra will be included in all of the analyses. A portion of the analysis also includes the Collection 4 data from MODIS. The AOD from MODIS and MISR has previously been compared to AERONET data (Abdou et al., 2005; Kahn et al., 2007a; Myhre et al., 2005); however, in this study these data are for model evaluation rather than for evaluation of the satellite data.

Figure 4 includes all available AERONET data for 2004 and the model results are sub-sampled for the same days and locations of measurements. Satellite data are sampled in the same way as the AERONET data (and the model). In Fig. 4 the averaged AOD values for AERONET, the model, and the satellite data are shown for regions where AERONET stations are grouped together with same colour code. Highest AERONET AOD values are found in Western and Eastern Asia and in Northern Africa and lowest over Australia and the Western part of North-America. The model underestimates AOD North-Africa and in East-Asia. In the other regions, the difference between the model and the AERONET AOD ranges from only a few percent to differences - of up to around 20\% (the largest difference is in South-America). Especially over East-Asia the satellite data compare well against the AERONET data in comparison with the model (maximum difference between satellite data and AERONET about $10 \%$ ). The best agreement between the model and the AERONET mean is over Australia and South-Africa which also is the case with the satellite data and the AERONET (the satellite data compares also very well with AERONET in South-America). Over Europe and North-America the satellite data deviates more from the AERONET data than the model, similarly in eastern North-America. The overestimation in the AOD for the satellite data in these regions compared to AERONET is around $20 \%$ and more in the western North-America. If we restrict the analysis of stations in western North-America to USA stations only, the AERONET mean value is slightly reduced. For the same AERONET stations the underestimation of AOD in the model compared to AERONET is almost unaltered whereas the overestimation of AOD in the satellite data compared to AERONET strengthens (around 50\% higher overestimations than values shown in Fig. 4). The average of all the annual mean 2004 AERONET data is 0.208 . For the model the average at these

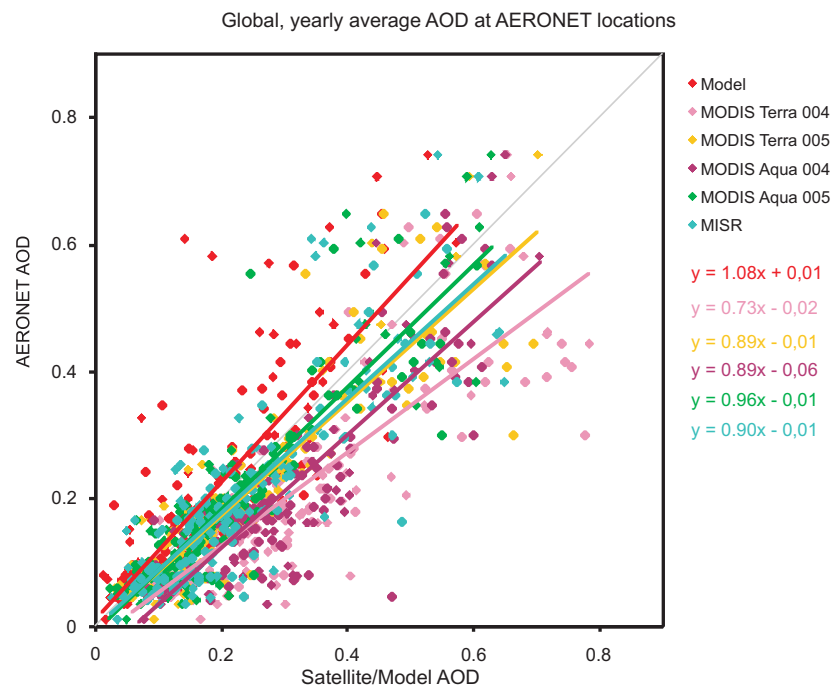

Fig. 5. Scatter plot of annual mean AOD from AERONET with satellite data and model results. Annual mean are calculated based on daily data from 2004 for days with available AERONET data.

stations is $10 \%$ lower, for MODIS Aqua 10\% higher, for MODIS Terra $16 \%$ higher, and for MISR it is $14 \%$ higher. The underestimation in the model compared to AERONET occurs to a large extent in East-Asia and North-Africa with smaller differences in other regions, on the other hand all the satellite data have, with only a few exceptions, an overestimation compared to AERONET data.

As already mentioned the satellite data are sampled in the same way as the AERONET data (and the model). However, since the satellite data have a limited spatial coverage the analysis shown in Fig. 4 include more AERONET data than satellite data. Screening the AERONET and satellite data so only measurements for same days are included in the analysis, resulted in only minor differences with some few exceptions. For MISR the difference in Southern Africa was reduced from $12 \%$ to $2 \%$ with this screening, whereas in the other regions the difference was changed by less than $5 \%$ with no systematic direction of the change. For MODIS the relative difference from the AERONET data was between 20 and $30 \%$ in the Northern Africa and this relative difference was reduced by $10 \%$ with identical screening. For the other regions the screening had as for the MISR data small impact on the relative difference between the AERONET and MODIS data. Ten of the AERONET stations with most data for 2004 were used for analysis of the importance of diurnal variation in AOD for February and August. The correlation coefficient changed by within $1 \%$ using AERONET data between 10 and 11 local time compared to diurnal mean values in evaluation with MISR and MODIS (Terra) data. It was a small reduction (4\%) in the overestimation of AOD in the MISR data compared to AERONET when analyzed with respect to data between 10 and 11 local time instead of diurnal mean. This feature was not found in the MODIS (Terra) data. 
Figure 5 shows a scatter plot of annual mean AOD data, with AERONET data on one side and model and satellite data on the other. The figure documents the underestimations of the AOD in the model, which is particularly evident for stations with high measured AOD. This corresponds with Fig. 4, where the model underestimation in north-Africa and Asia is illustrated. The satellite data overestimate the annual mean AOD compared to AERONET, however, substantial progress from Collection 4 to Collection 5 has been made for MODIS data.

Figure 6 shows the correlation coefficient from the model against the AERONET data in decreasing order. The correlation coefficients between satellite data from MODIS and MISR versus AERONET data are also shown. The analysis is based on daily mean AERONET data. Correlation coefficients with AERONET are mostly lower for the model compared to the satellite data but the differences are not large. Correlation coefficients for MISR for some stations are lower than for MODIS, but some of the highest correlation coefficients are found for MISR. This is somewhat related to the fewer data points for MISR due to more limited spatial coverage for MISR than MODIS. The ratio of the annual mean AOD from the model and satellite retrievals to the AERONET data is shown in Fig. 7. In addition, the number of days with measurements for the AERONET sites as well as the AERONET annual mean AOD is shown in the figure. The model has few values outside a factor of two of the AOD of the AERONET sites (ratios less than 0.5 or higher than 2 ) and these are mostly underestimations. For the satellite data this situation is reversed, as there are almost exclusively overestimations for the satellite data which are more than a factor of 2 from the AERONET data.

In Fig. 8 all daily AERONET data available for 2004 are included in the scatter plot analysis. The correlation coefficient and the regression line are given for the model, MISR, and the two MODIS satellite data sets. The correlation coefficient is lower for the model compared to the satellite data, which is in accordance with Fig. 6, but with a slope closer to one (and the largest offset from $\mathrm{x}$-axis). The MODIS Collection 5 has better correlation coefficients and regression lines than the Collection 4 data (not shown). The model clearly underestimates a large fraction of high AERONET AOD values, which are better reproduced in the satellite data.

To illustrate regions where the model performs well and regions where the model shows weaknesses we have chosen 20 AERONET stations that have a high daily AOD coverage (Fig. 9). Our aim here is to emphasize the use of daily data to investigate whether the model is able to reproduce day to day variations.

The magnitude of AOD and daily variations are particularly well represented at FORTH Crete, El Arenosillo, Lake Argyle, Mongu, and GSFC. GSFC is located on the east coast of the US where industrial aerosols dominate. Here seasonal and daily variations as well the level of AOD is in good agreement between the model and AERONET and this agreement is typical for this region. FORTH Crete, located in Southern Europe, is also located largely influenced by industrial aerosols, but show less seasonal variation than at GSFC. At other European stations such as Mainz and Moldova the correlations are lower but the magnitude of AOD show reasonable agreement (note that some high modelled AOD values occur during periods with no AERONET values, indicating cloudy periods). At Venice, the modelled AOD is underestimated, which is typical for the Po Valley region (Myhre et al., 2009) but at Lecce which is situated further south, the AOD (and the correlation) is in better agreement. As shown in Fig. 4 and discussed earlier, the model underestimates the AOD slightly in the western US and the Rodgers Dry Lake station, with correlations that are relatively weak. The daily variation in modelled AOD is correlated rather well with the AERONET data at El Arenosillo, a European station influenced by mineral dust from Sahara. The station at Blida (Northern Africa), which is closer to the mineral dust sources than El Arenosillo, has a weaker correlation in daily AOD. Especially at Ouagadougou the model underestimates and reproduces the mineral dust events inadequately (the Ångstrøm exponent shows that mineral dust is the dominating aerosol compound and the amount of biomass burning aerosols are small). The AOD level is better reproduced in Dakar than at Ouagadougou, showing a slightly higher correlation; however, the failure to reproduce some of the mineral dust events is observed. These deficiencies in the model are likely to be associated with the dust emissions. In Southern Africa, we find that those sites situated closest to the major biomass burning regions show the poorest correlation. This can be expected since in the model monthly mean biomass burning emissions are used and stations close to source regions are more dominated by the daily fires than stations further away, where meteorological factors (such as transport and removal) are important (Myhre et al., 2003a). At the two South American stations Alta Floresta and Sao Paulo, the model overestimates the AOD but the seasonal variation is reproduced and to some extent the daily variations (correlation coefficients of around 0.5). The correlation between the model and the AERONET data ranges from high (Lake Argyle) to medium (Sede Broker, Dhabi, Darwin, and Ascension Island) for the remaining five stations. Ascension Island has two maxima during the year due to the biomass burning in Africa and these are also reproduced in the model, whereas the day to day variation is only moderately reproduced.

At many AERONET stations the satellite data follows the day to day variation in AOD and the level of AOD better than the model (such as at Dakar and Alta Floresta). However, it can easily be seen that the MODIS data have higher AOD at Rodgers Dry Lake than the AERONET; this station is in a region with a large difference between the model and the satellite data (Fig. 4).

In terms of RF, the underestimation (up to one third) of the AOD in East Asia in the model compared to AERONET data is the most important since most of the aerosols in this region 


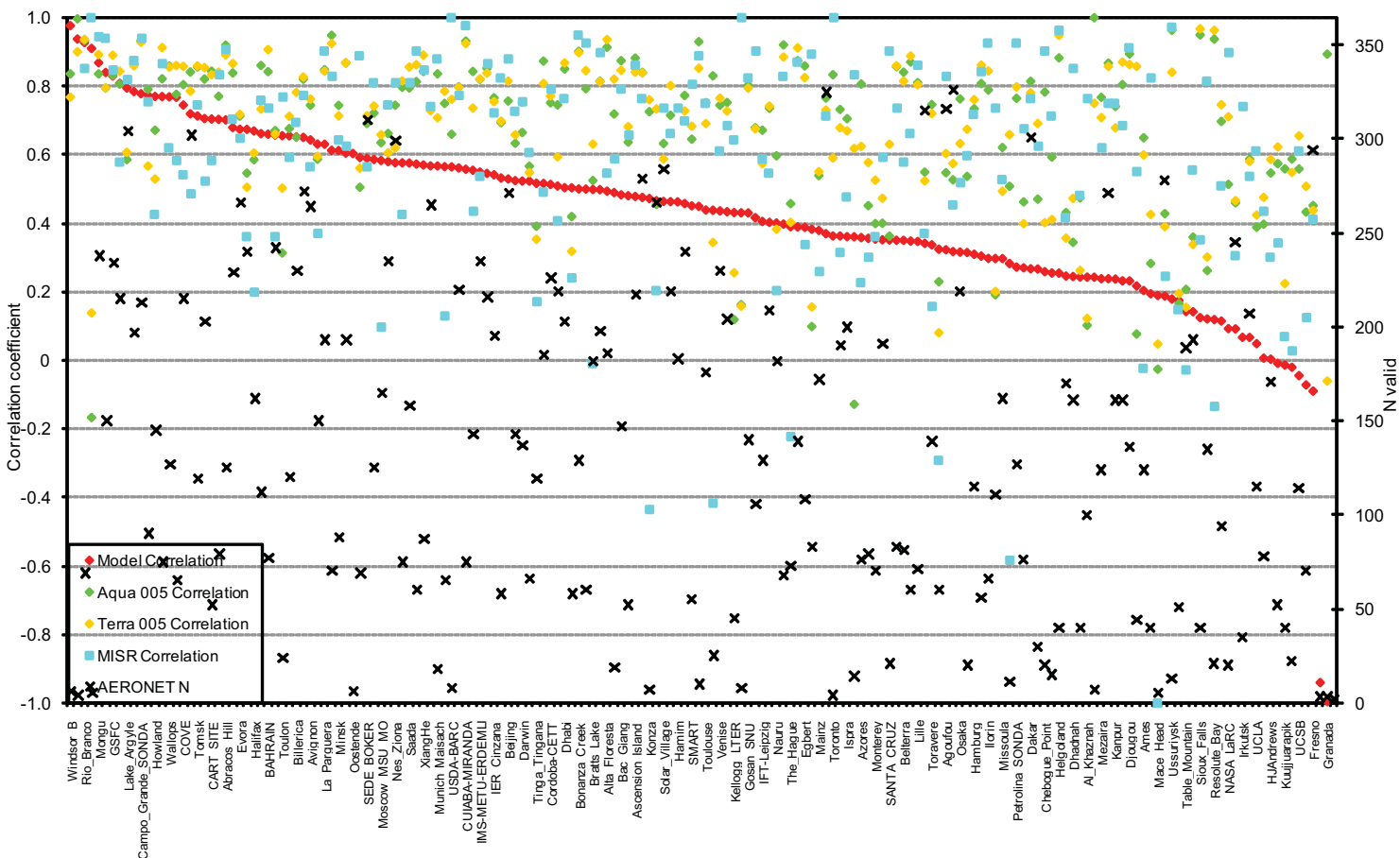

Fig. 6. Correlation coefficient between daily AOD from AERONET versus model results for the year 2004. Correlation coefficients between daily AERONET data and satellite data are also shown. The correlation coefficient is shown in decreasing order for the model. Number of AERONET observations shown on the right axis.

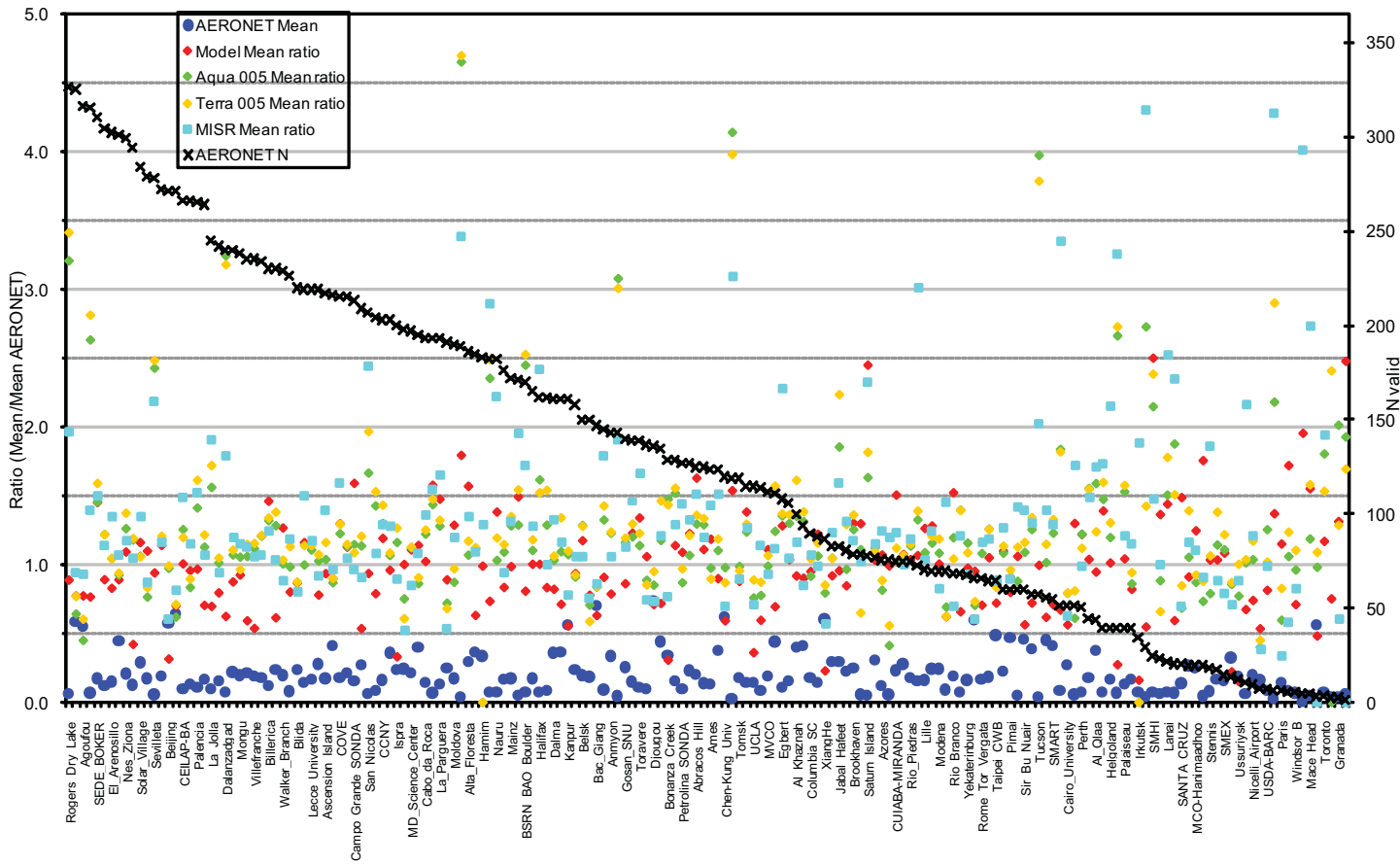

Fig. 7. Ratio of the annual mean AOD from the model and satellite data with AERONET AOD. Number of AERONET observations shown on the right axis. Data for the model and the satellites included only for days with AERONET data. The AERONET annual mean AOD is shown with blue colours. 

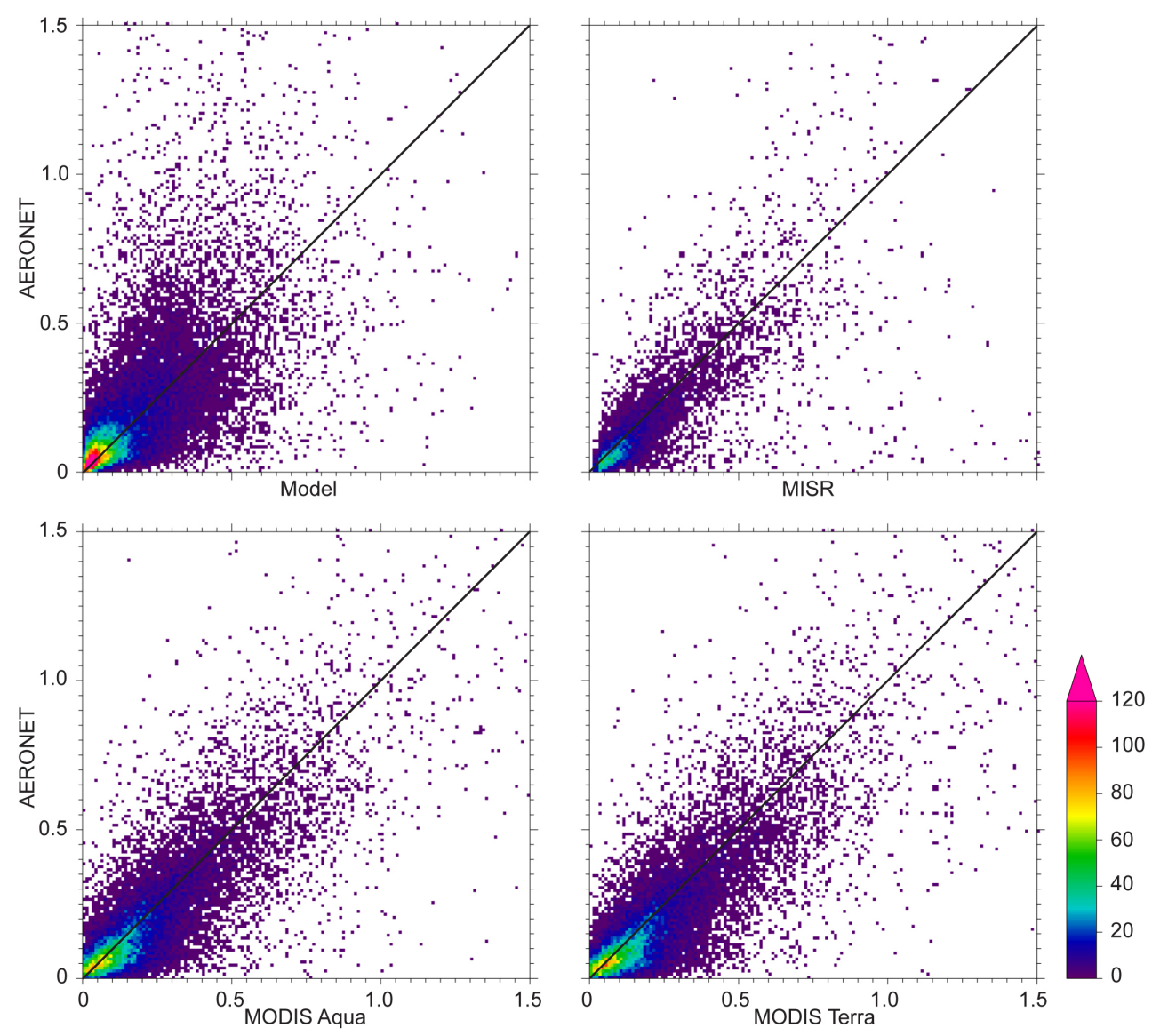

Fig. 8. Scatter plot of all AERONET AOD data available for 2004 with model results and satellite data. The colour codes shows number of points within a 0.01 AOD interval.

are of anthropogenic origin. The model also underestimates AOD in Northern Africa, but this is of less importance for RF since it is mostly related to natural aerosols. Other differences in AOD between AERONET and the model at regional and temporal scale are small.

\subsection{Comparison with global satellite data}

The geographical distribution of the annual mean AOD $(550 \mathrm{~nm})$ from the model is compared to satellite data in Fig. 10. Satellite data from MODIS (Collection 5) and MISR (see description above) have been included in the analysis and daily data are adopted. The spatial coverage of the daily satellite data varies substantially. Therefore we have screened the daily modelled AOD data in a similar way as the three satellite data. This causes the annual mean AOD from the model to vary somewhat in the figure since the selection of the daily data varies.

There are several similarities in the three satellite data sets and in that obtained by the model, as shown in other studies (Forster et al., 2007; Kaufman et al., 2002; King et al., 2003; Remer et al., 2005). In comparison with the satellite data, the model overestimates the AOD in South-America and in the outflow from Central America. The model has much lower values at high latitudes compared to the satellite data as well as over the western US, China (compared to MODIS), the Middle East, in the Ganges region in India, and in the outflow from the Asian continent.

The maximum in AOD in central South-America is mainly from biomass burning. The geographical pattern in the AOD is quite similar in the model compared to the MODIS data but unlike in the biomass burning areas in Southern Africa, the AOD is overestimated. The overestimation in AOD in the outflow from Central America is due to sulphate aerosols in the model, and is not related to mineral dust from Sahara. At high northern latitudes, the model has substantially lower AOD than in the satellite data both over ocean and land. In the AEROCOM exercise, the Oslo CTM2 was among the global aerosol models with lowest fraction of aerosols poleward of 80 degrees (Textor et al., 2006) as well as a low amount of BC (Schulz et al., 2006). In comparison with AERONET data, the model underestimates the AOD by almost $40 \%$ for the mean of the three stations north 

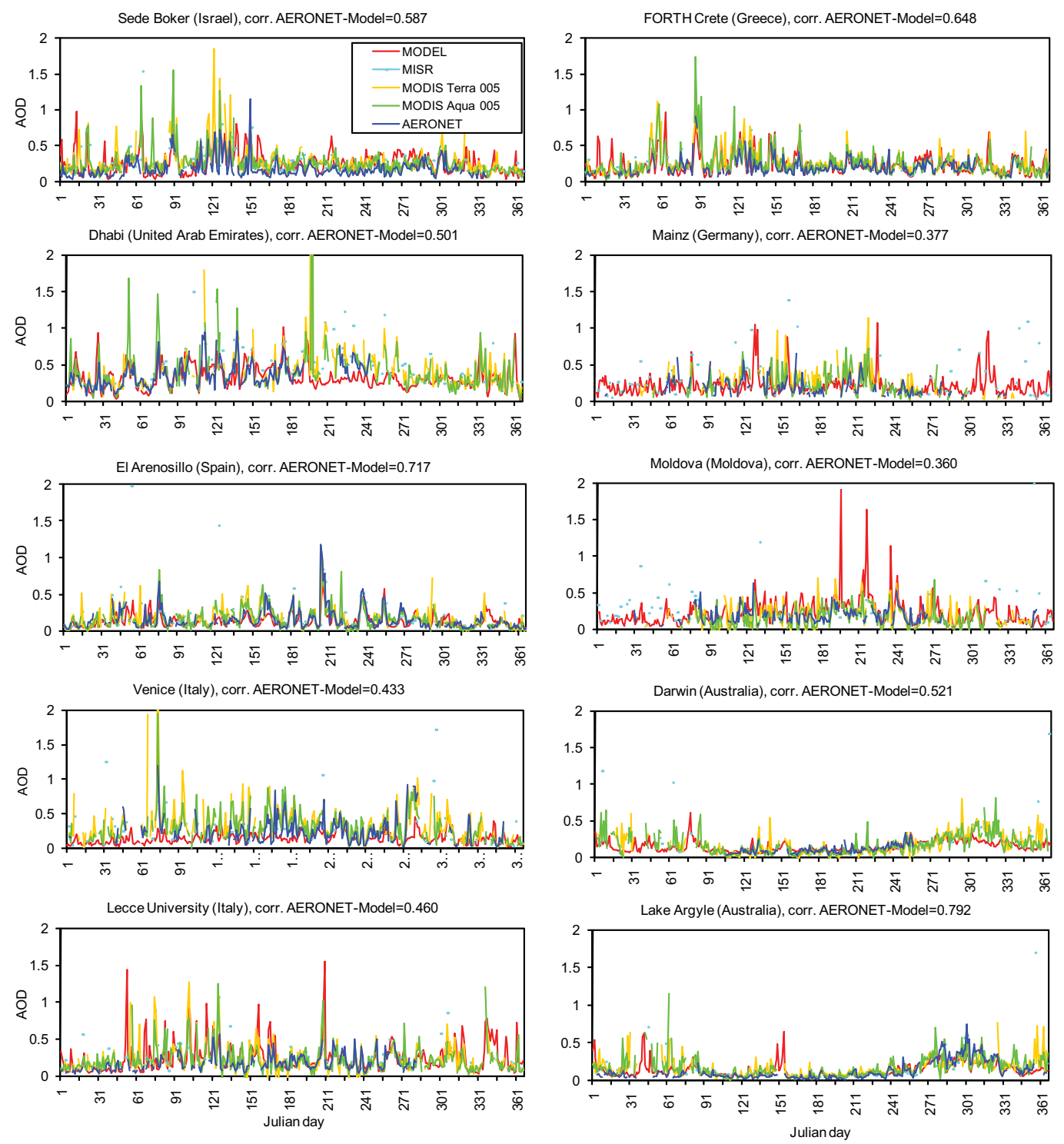

Fig. 9a. Daily variation in AOD at selected AERONET stations. In addition to results from AERONET, model results and satellite data are shown. The correlation coefficient between AERONET and model AOD is shown in the heading of each panel. The stations with most AERONET data available for 2004 and various regions are chosen.

of 70 degrees (Longyearbyen, Resolute Bay, and Barrow). In contrast, the satellite data overestimate the AOD compared to AERONET at these stations by more than $60 \%$. The difference in AOD between the model and the satellite data over most of Russia is also substantial. The mean of three AERONET stations in this region (Yaktusk, Yekaterinburg, and Tomsk) is around 10\% lower in the model than the AERONET values, whereas the MODIS data are overestimated by the same magnitude as the model underestimates the AOD. The corresponding MISR mean AOD value is very close to the AERONET mean. The quality of the satellite retrievals is reduced over highly reflective surfaces, and snow contamination may be a problem at high latitudes and is strongly improved in the Collection 5 data compared to Collection 4 (not shown). Missing emissions from wild fires may be one cause for the lower model values.

(Ohara et al., 2007) showed that emissions in China have increased since 2000 (emission inventory used for this year or earlier in the model simulations) and that the spatial pattern of the emissions of carbonaceous aerosols in the Ganges region has a pattern similar to the AOD provided by satellites. Further, the carbonaceous aerosol emissions reported by Ohara et al. (2007) for India are about a factor of two higher (lower than a factor of two for $\mathrm{BC}$ and more than a factor of two for OC) than in Bond et al. (2004) for India. For China, the estimates by Ohara et al. (2007) and Bond et 

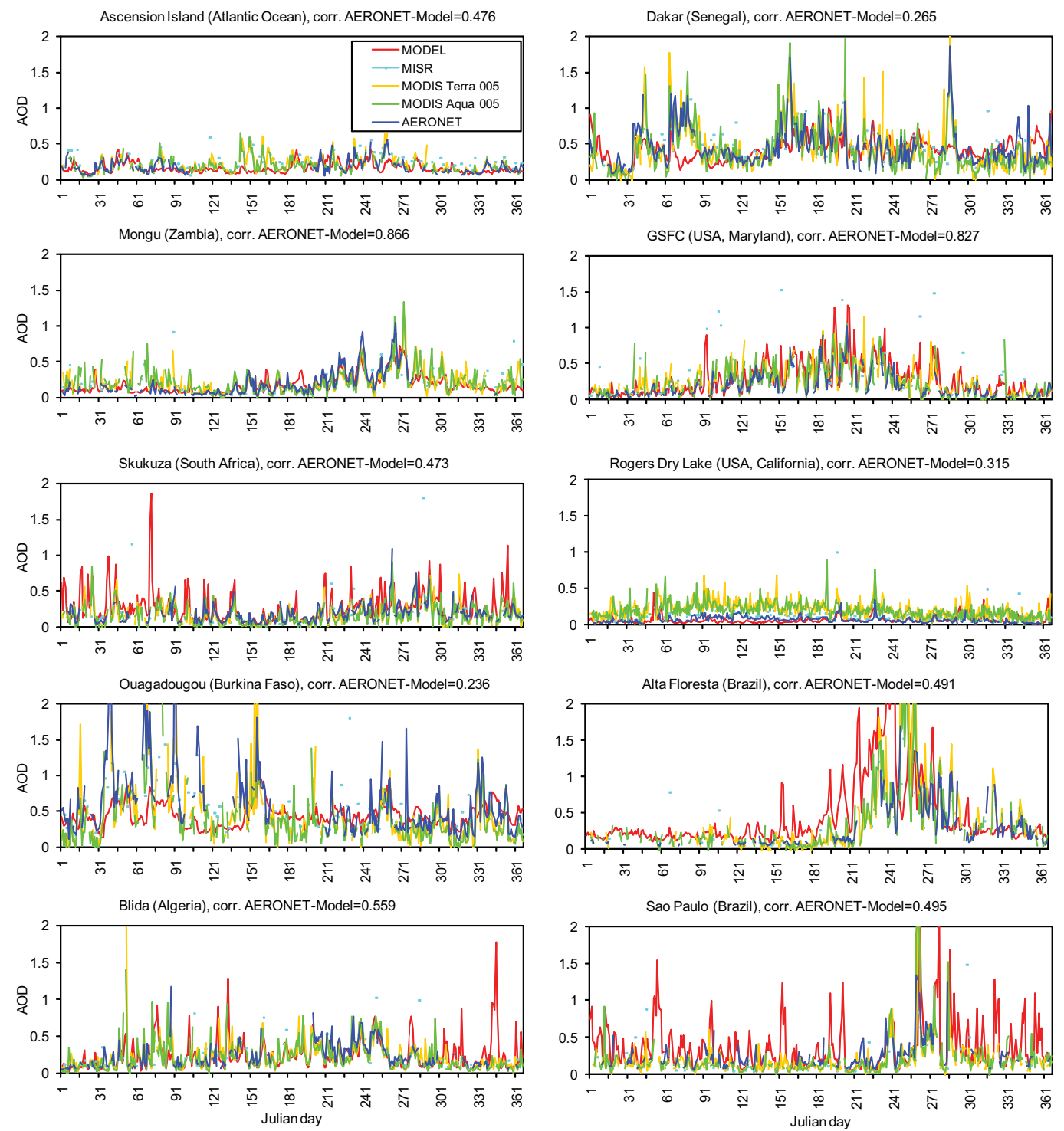

Fig. 9b. Continued.

al. (2004) are in reasonable agreement for BC for the year 1996. After 1996, Ohara et al. (2007) estimate a reduction. For OC, Ohara et al. (2007) estimate a larger emission than Bond et al. (2004). However, for China the largest contributor to higher emissions compared to what used in this study is for $\mathrm{SO}_{2}$ with $35 \%$ higher emissions for 2000 and thereafter a similar in magnitude increase in $\mathrm{SO}_{2}$ emissions between 2000 and 2003 (Ohara et al., 2007).

For the RF simulations discrepancy in AOD between satellite retrievals and the model is important. The AOD from the satellite data is substantially higher than in the model at high northern latitudes, at latitudes above 60 degrees this is up to a factor of 10 higher. The AOD in the satellite data are at least a factor of two higher several places in Asia. This is also similar for the outflow from Asia over the northern Pa- cific Ocean. Differences occur in other regions with anthropogenic aerosols as well, but magnitude of it is smaller and variable whether overestimations or underestimations take place.

\subsection{Single scattering albedo and Ångstrøm exponent}

Much emphasis has been given above to the AOD since it is a proxy for the aerosol loading and a lot of data are available. This section deals with two other important optical properties, the single scattering albedo $(\omega)$ and the asymmetry factor $(\mathrm{g})$. The asymmetry factor is dependent on the aerosol size and cannot be directly measured by remote sensing. The Ångstrøm exponent (King et al., 1999; Nakajima and Higurashi, 1998) provides aerosol size information, 

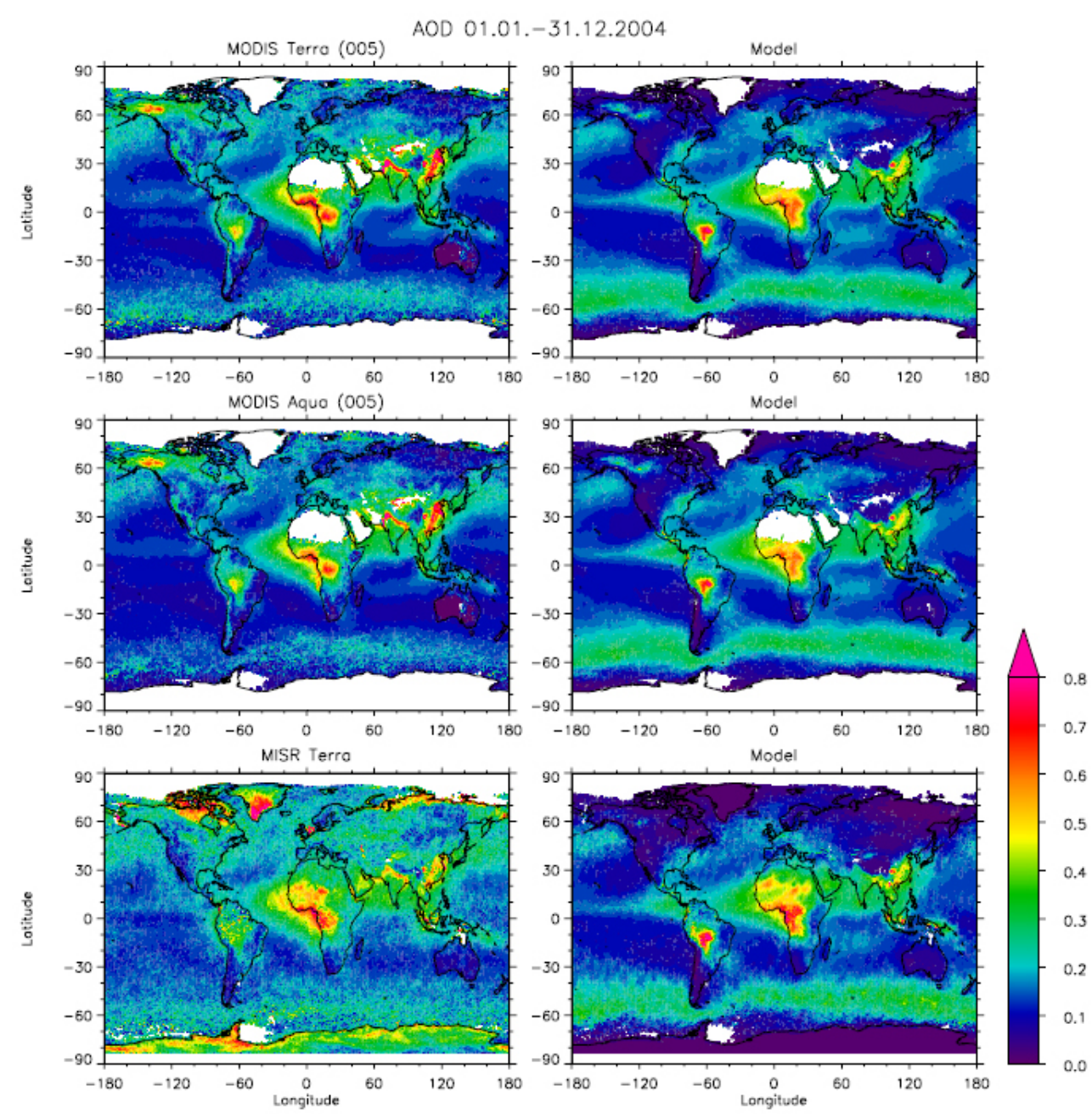

Fig. 10. Annual mean AOD from MODIS (Terra), MODIS (Aqua), MISR in the left column based on available daily level 3 products. The right column shows modelled AOD with screening criteria equal to the daily satellite data in the same row in the left column. The model AOD in the right column differs only due to different sampling of the results.

showing small values for large aerosols and large values for small aerosols. The modelled values are shown for two sets of single scattering albedo; i.e. one with a standard fossil fuel $\mathrm{BC}$ absorption of around $7.5 \mathrm{~m}^{2} / \mathrm{g}$ (Bond and Bergstrom, 2006; Bond et al., 2006) and one with the BC absorption enhanced to take into account mixing with other aerosol types. The latter is taken into account by enhancing the absorption of hydrophilic BC by $50 \%$ according to Bond et al. (2006).

Figure 11 shows the single scattering albedo for some selected AERONET stations (these are selected mainly due to the number of measurements in 2004 and location). The figure is grouped into four regions. The model follows the variation of the AERONET single scattering albedo between the various stations to a large degree. The best agreement between the model and the AERONET single scattering albedo is found for the industrialized regions in Europe and North America. The model single scattering albedo is often slightly higher than the measured data, in particular for Africa. The single scattering albedo for the model is reduced when the enhanced BC absorption is taken into account, in particular over regions where fossil fuel and bio fuel $\mathrm{BC}$ are the dominating factors for the single scattering albedo. The agreement between the model and the observations is slightly improved compared to the standard case.

A scatter plot of the annual mean single scattering albedo from AERONET compared to modelled data is shown in Fig. 12. All stations are included in the figure. The results show some scatter in the single scattering albedo between the AERONET data and the model but the results follow the 1:1 line in general terms. A large fraction of the modelled single scattering albedo has values $0.02-0.03$ higher than AERONET. Note that many of the low observed values of single scattering albedo are reproduced with the model. Similar to Fig. 11, the enhanced BC absorption 

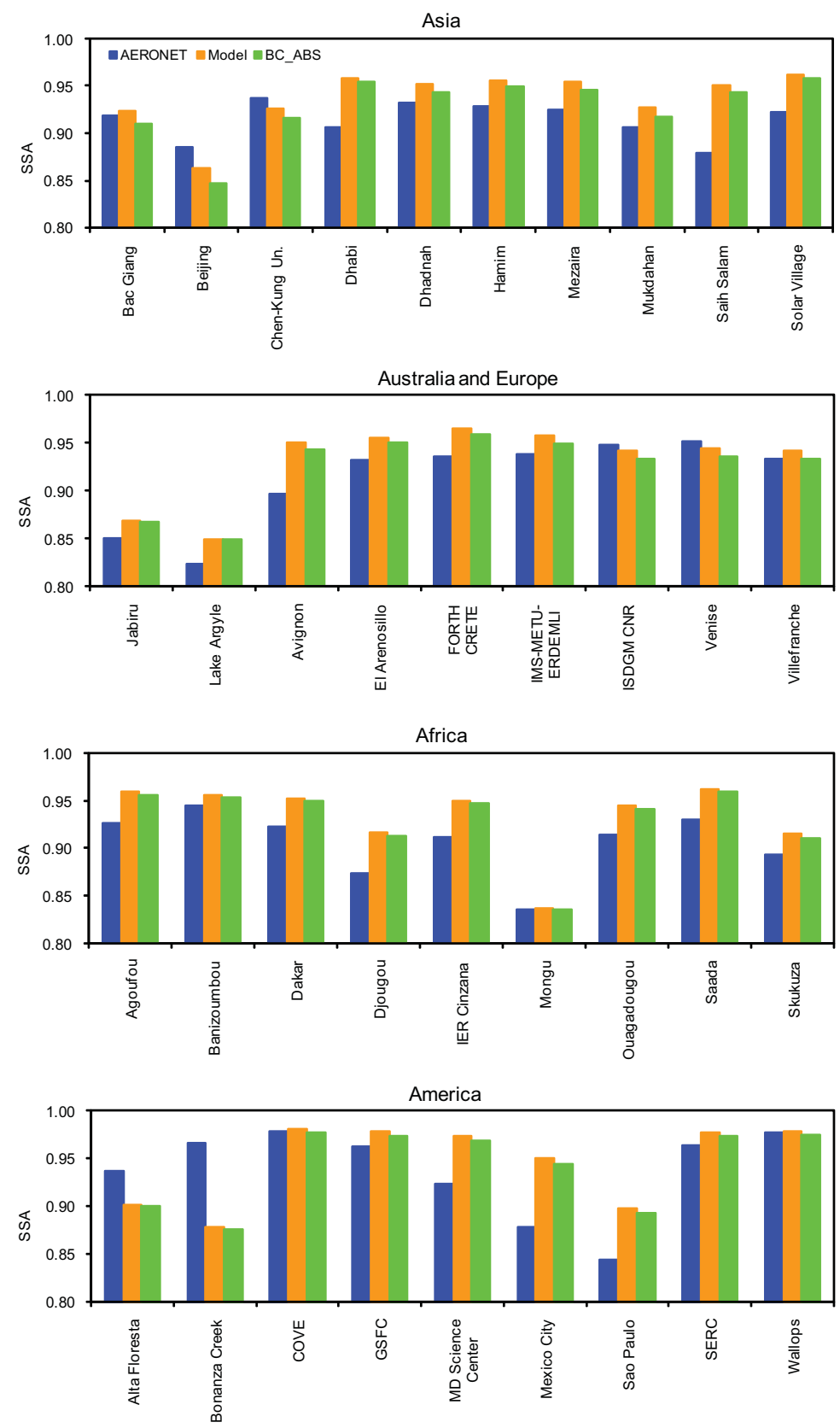

Fig. 11. Comparison of single scattering albedo (SSA) (at $550 \mathrm{~nm}$ ) between AERONET and the model for the standard version (model) and the increased $\mathrm{BC}$ absorption version in order to represent internal mixture (BC_ABS). The AERONET data at $550 \mathrm{~nm}$ are derived as mean of 440 and $670 \mathrm{~nm}$ data.

to take into account mixing reduces the single scattering albedo, but the differences are relatively small. Some of the outliers disappear when only more than 10 daily AERONET observations are considered in the analysis (not shown). The slope and correlation coefficient is close to 0.6. The mean SSA for the 125 AERONET stations with available SSA observations is 0.923 , whereas it is 0.940 when the model is run with the standard version and 0.933 with the enhanced $\mathrm{BC}$ absorption, respectively.
Figure 13 shows a scatter plot of the annual mean Ångstrøm exponent. The AERONET Ångstrøm exponent is derived from the wavelengths 500 and $870 \mathrm{~nm}$, whereas in the model it is derived from 550 to $870 \mathrm{~nm}$. The agreement in the Ångstrøm exponent between the model and observations shown in Fig. 13 indicates that the aerosol sizes are reasonably described in the aerosol model. Only seven of the 182 stations are recognized as outliers. 


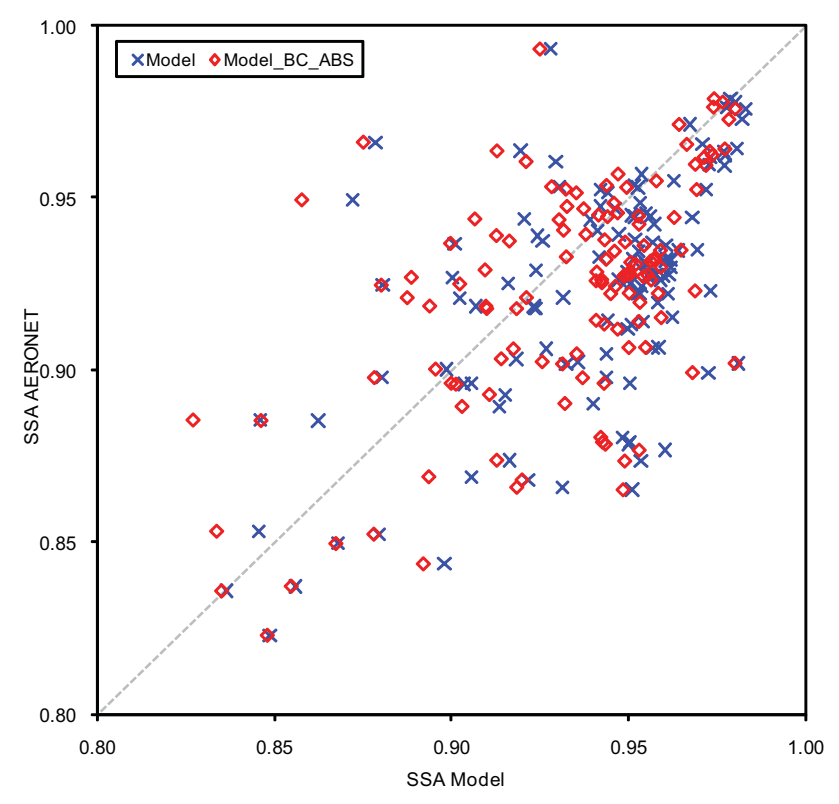

Fig. 12. Scatter plot of single scattering albedo (SSA) between AERONET measurements and the Oslo CTM2. Two model versions are compared to the AERONET data, namely the model for the standard version (model) and the increased BC absorption version in order to represent internal mixture (BC_ABS).

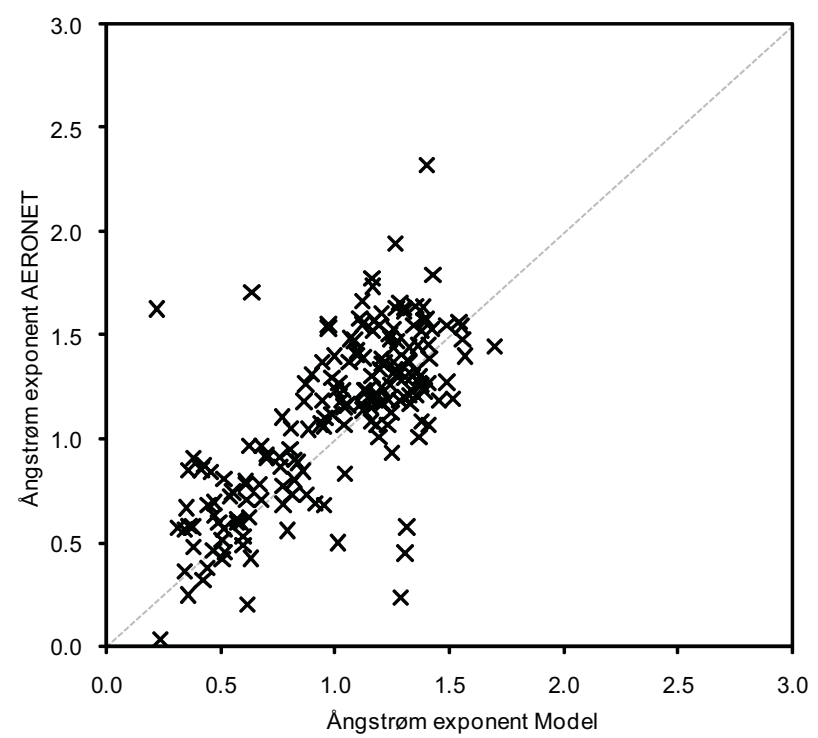

Fig. 13. Scatter plot of the annual mean Angstrøm exponent between AERONET measurements and the Oslo CTM2. The AERONET Ångstrøm exponent is derived for data at wavelength between 500 and $870 \mathrm{~nm}$, whereas for the model between 550 and $870 \mathrm{~nm}$.

For the RF calculations the mean difference of almost 0.02 in SSA in the standard simulation is crucial. However, it should be noted the largest difference between measurements and the model is in Northern Africa and not necessarily re-

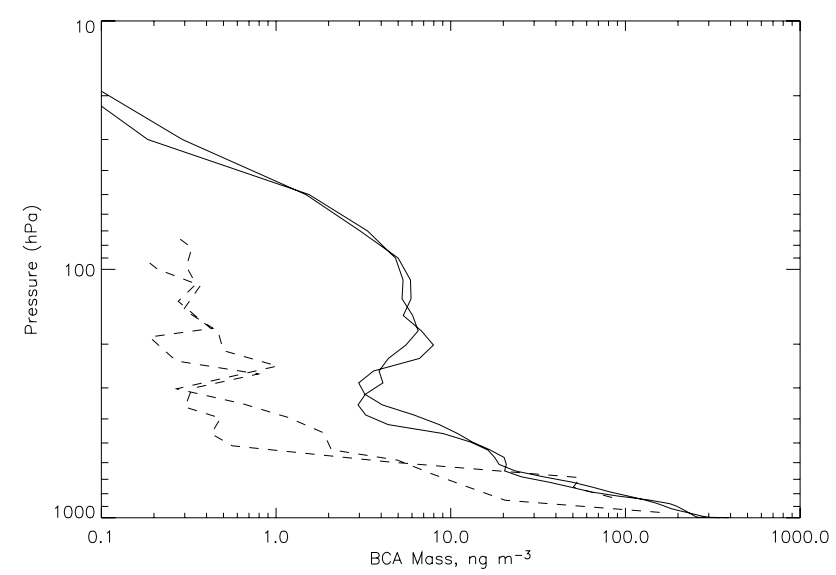

Fig. 14. Vertical profile of $B C$ from observations (dotted line) and the aerosol model (solid line) for two different days in November 2004.

lated to anthropogenic aerosols. The small difference between measurements and the model for the Ångstrøm exponent should be of small importance for the RF.

\subsection{Aerosol vertical profile}

Absorbing aerosols above a cloud layer have a substantially larger RF than if the aerosols are situated below the clouds, therefore the vertical profile of aerosols, and in particular the profile for $\mathrm{BC}$ is important. Despite this the number of available observations of the vertical profile of $\mathrm{BC}$ is scarce. Schwarz et al. (2006) showed that there were substantial differences between two global aerosol models when compared to aircraft measurements of the vertical profile of $\mathrm{BC}$ over North America. One of the models compared well with the observations, whereas the other overestimated the $\mathrm{BC}$ concentration by one to two orders of magnitude in the upper troposphere. Figure 14 shows a comparison of the aircraft measurements reported by Schwarz et al. (2006) and the Oslo CTM2 modelled data for BC for two days in 2004 . The aerosol model predicts higher $\mathrm{BC}$ concentrations than the observations for almost the entire column, and for both days. The reduction of $\mathrm{BC}$ concentration with altitude is weaker in the model than observed, with the largest differences at altitudes higher than at 400-500 hPa. In the upper troposphere and lower stratosphere the modelled BC concentration is almost an order of magnitude larger than that observed. However, the concentration is still low and significantly lower than at the surface.

The Oslo CTM2 has been compared with aircraft measurements of the vertical profile measured during four aerosol campaigns, comparing particularly well on the upper boundary of the aerosol plume (Myhre et al., 2003a, $b, 2008,2009)$ for a mixture of different aerosol types. The largest difference with respect to the vertical profile as compared to observations has been for the DABEX campaign 

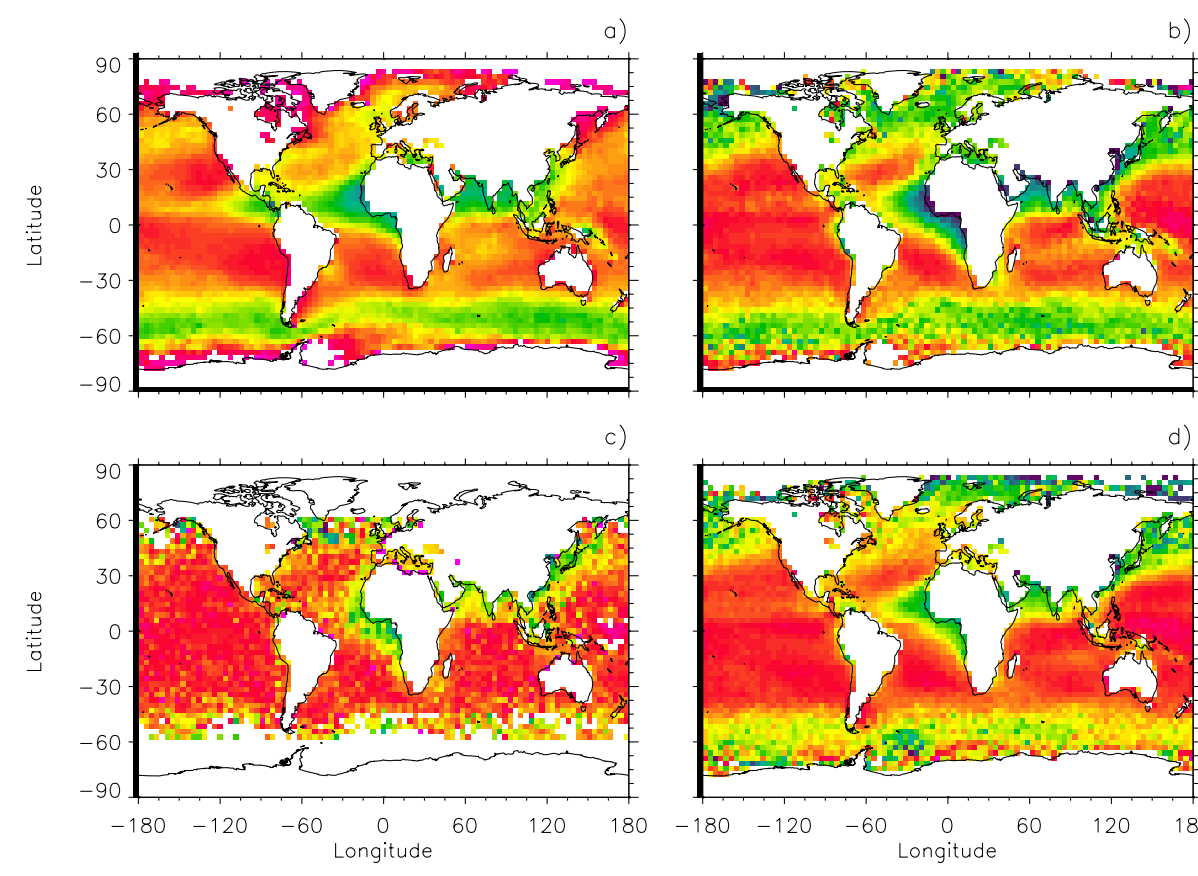

b)
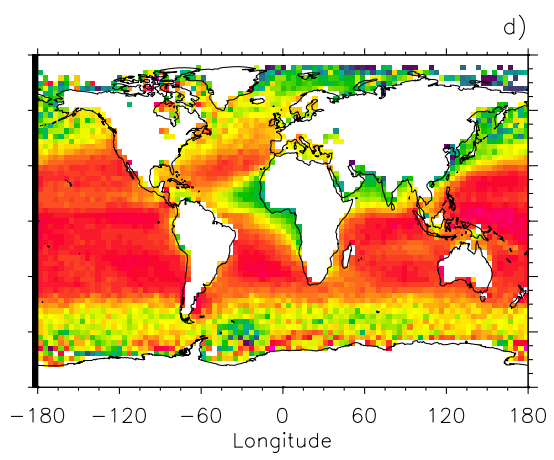

$W m^{-2}$

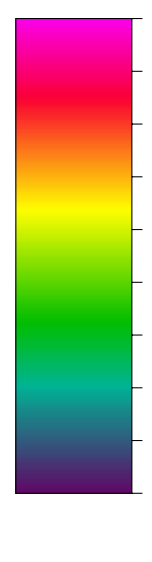

0.0

$-2.0$

$-4.0$

$-6.0$

$-8.0$

$-10.0$

$-12.0$

$-15.0$

$-20.0$

$-25.0$

Fig. 15. The solar direct radiative effect (DRE) of aerosols over ocean for clear sky conditions for annual mean condition of 2004, (a) Oslo CTM2, (b) MODIS-R, (c) MODIS-CERES-C, (d) MODIS-CERES-L.

with a combination of mineral dust and biomass burning aerosols in the lower part of the aerosol plume which were strongly underestimated and overestimated, respectively.

\subsection{Comparison of direct aerosol radiative effect over ocean}

We have compared the modelled direct radiative effect of aerosols (DRE) over the ocean with three satellite derived estimates. Aerosol models have had a tendency to underestimate the DRE compared to satellite data (Yu et al., 2006) and here we compare against three estimates to investigate the robustness of the model - satellite differences. It has earlier been shown that the Oslo CTM2 does not significantly underestimate the DRE compared to the POLDER satellite data set (Myhre et al., 2007).

The satellite derived estimates included in this analysis are. i) MODIS-R: The aerosol model used in the MODIS satellite retrieval is adopted to determine the aerosol optical properties and along with the AOD and an off-line radiative transfer model, the DRE of aerosol is calculated (Remer and Kaufman, 2006). The MODIS-R data used in this study is based on the Collection 5 data. ii) MODIS-CERES-C: The MODIS aerosol product is combined with the CERES data to derive the DRE (Christopher and Zhang, 2002; Zhang et al., 2005). iii) MODIS-CERES-L: MODIS and CERES data are combined to calculate the DRE of aerosols on a smaller spatial scale than for the CERES footprints (Loeb and Kato, 2002; Loeb and Manalo-Smith, 2005). Monthly mean data for 2004 are used for the model and satellite derived estimates in this comparison, except for MODIS-CERES-L where monthly mean data for 2001 is adopted.

Figure 15 shows the DRE of aerosols from the model and the three satellite derived data sets. The DRE from satellites are so far mostly derived over ocean and includes both anthropogenic and natural aerosols. Several studies have shown that the DRE has the strongest values off the coast of western Africa as well as strong values in coastal regions in south and east Asia (Boucher and Tanré, 2000; Christopher and Zhang, 2002; Loeb and Kato, 2002). Figure 15 shows strong values at high southern latitudes over ocean and some of the satellite derived estimates have strong DRE at northern latitudes. The global mean DRE over ocean for the model, MODIS-R, MODIS-CERES-C, MODIS-CERES-L is $-6.1,-7.2,-5.2$, and $-6.1 \mathrm{Wm}^{-2}$, respectively.

Figure 16 shows normalized values of the radiative effect of aerosols (direct radiative effect of aerosols divided by AOD) (NRE). The model has NRE weaker than MODIS$\mathrm{R}$ and stronger than MODIS-CERES-C, but quite similar to MODIS-CERES-L. The strengthening in the NRE at high latitudes is due to increased backscattering for high solar zenith angles (Haywood and Shine, 1997; Myhre and Stordal, 2001). Several causes for the differences in the satellite derived NRE may exist: Conversion from instantaneous to daily mean DRE can be a reason, likewise the estimation of the clear sky, angular models used to convert CERES radiances to fluxes, and for MODIS-R the assumption of constant surface albedo may bias the DRE towards 


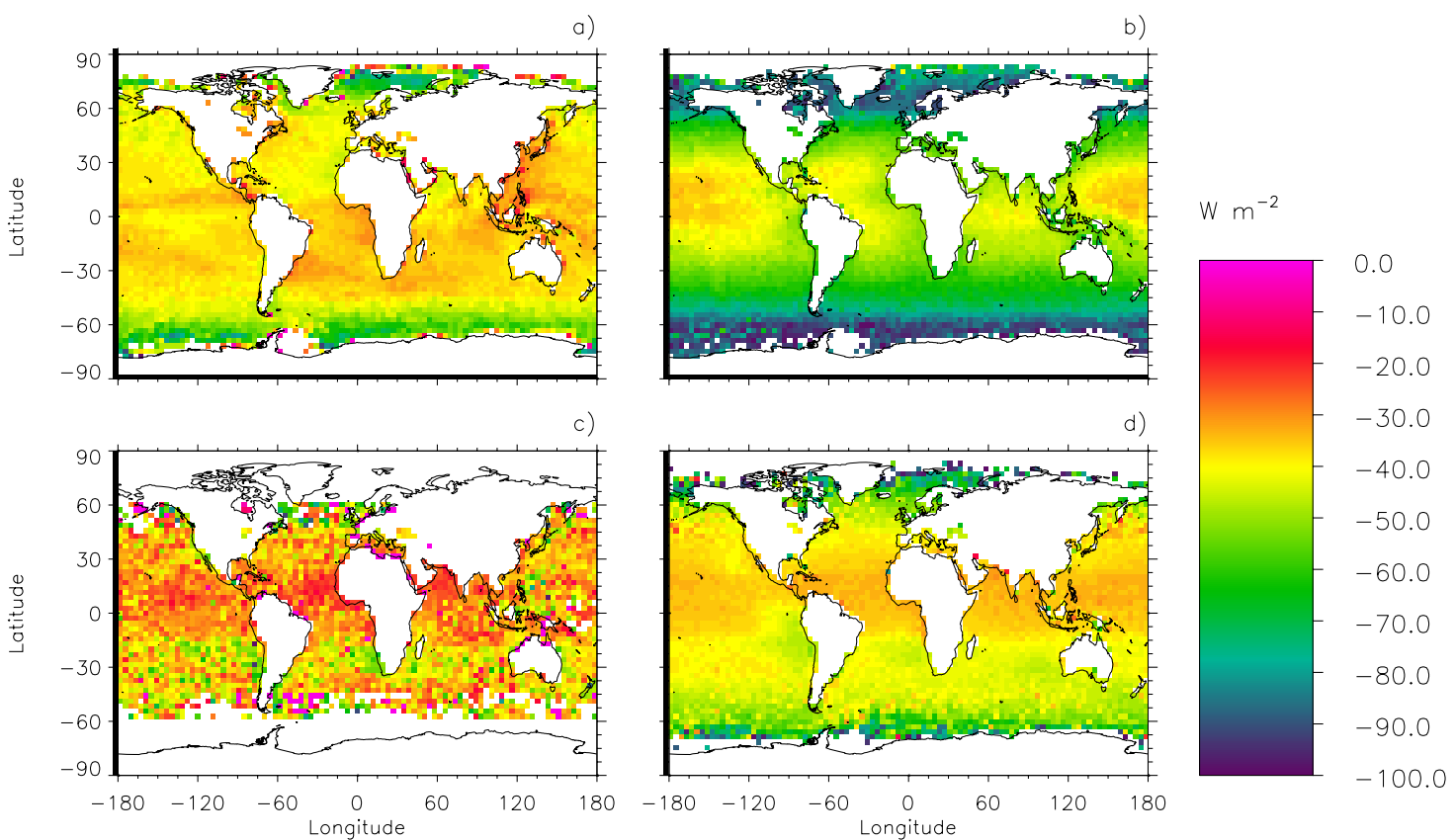

Fig. 16. The normalized solar radiative effect (NRE) (DRE divided by AOD) of aerosols over ocean for clear sky conditions for annual mean condition of 2004, (a) Oslo CTM2, (b) MODIS-R, (c) MODIS-CERES-C, (d) MODIS-CERES-L.

more negative values at high latitudes. Christopher and Jones (2009) found good consistency between the MODISCERES-C and MODIS-R methods for a 5 years period with many regions having differences of less than $5 \mathrm{Wm}^{-2}$ in the instantaneous NRE, but also some regions with larger difference mostly at higher latitudes and small AOD.

The model has a weaker DRE than the satellite estimates over ocean off the coast of East Asia and this is most likely due to an underestimation of AOD as seen in Fig. 10 and only to a minor extent the NRE since the model has a NRE only slightly weaker than the satellite data. Similarly, the stronger DRE in the model off the coast of central-America is mostly a result of too high AOD in this region (Fig. 10). At high northern latitudes the difference in the model and the satellite for the DRE is mostly due to lower AOD in the model (at least compared to MODIS-CERES-L, whereas compared to MODIS-R it is also due to difference in NRE).

Figure 17 shows the DRE for 13 regions. Except for the regions 0-4 the model has DRE values close to the MODIS$\mathrm{R}$ data. The differences in the DRE at high northern latitudes shown in Fig. 17 can also be seen in Fig. 15.

The comparison of satellite derived and model calculated DRE and NRE are difficult to apply in RF calculations due to the large variation in satellite derived values. However, the model has NRE values very close to one of the satellite derived data sets and the mean of the three data sets.

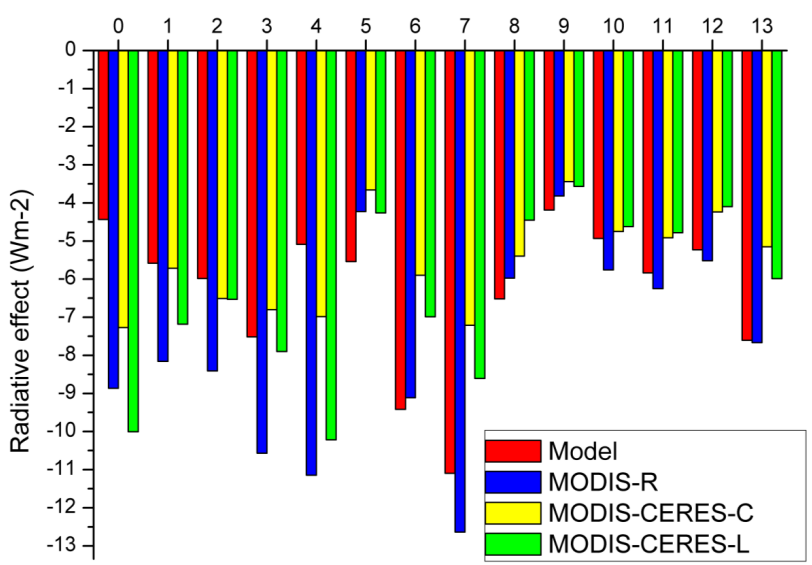

Fig. 17. Regional direct radiative effect (DRE) of aerosols over ocean for clear sky conditions for annual mean condition of 2004. Regions as in (Yu et al., 2006) in addition a region at latitudes higher than 60 degree north is included (region 0 ).

\subsection{Anthropogenic changes}

\subsubsection{Anthropogenic fraction of AOD}

By definition of RF, it is only the anthropogenic AOD that is included in the RF estimates. The anthropogenic fraction of AOD has been estimated from models and satellite retrievals (Kaufman et al., 2005; Schulz et al., 2006). The anthropogenic AOD fraction simulated in this work is shown 

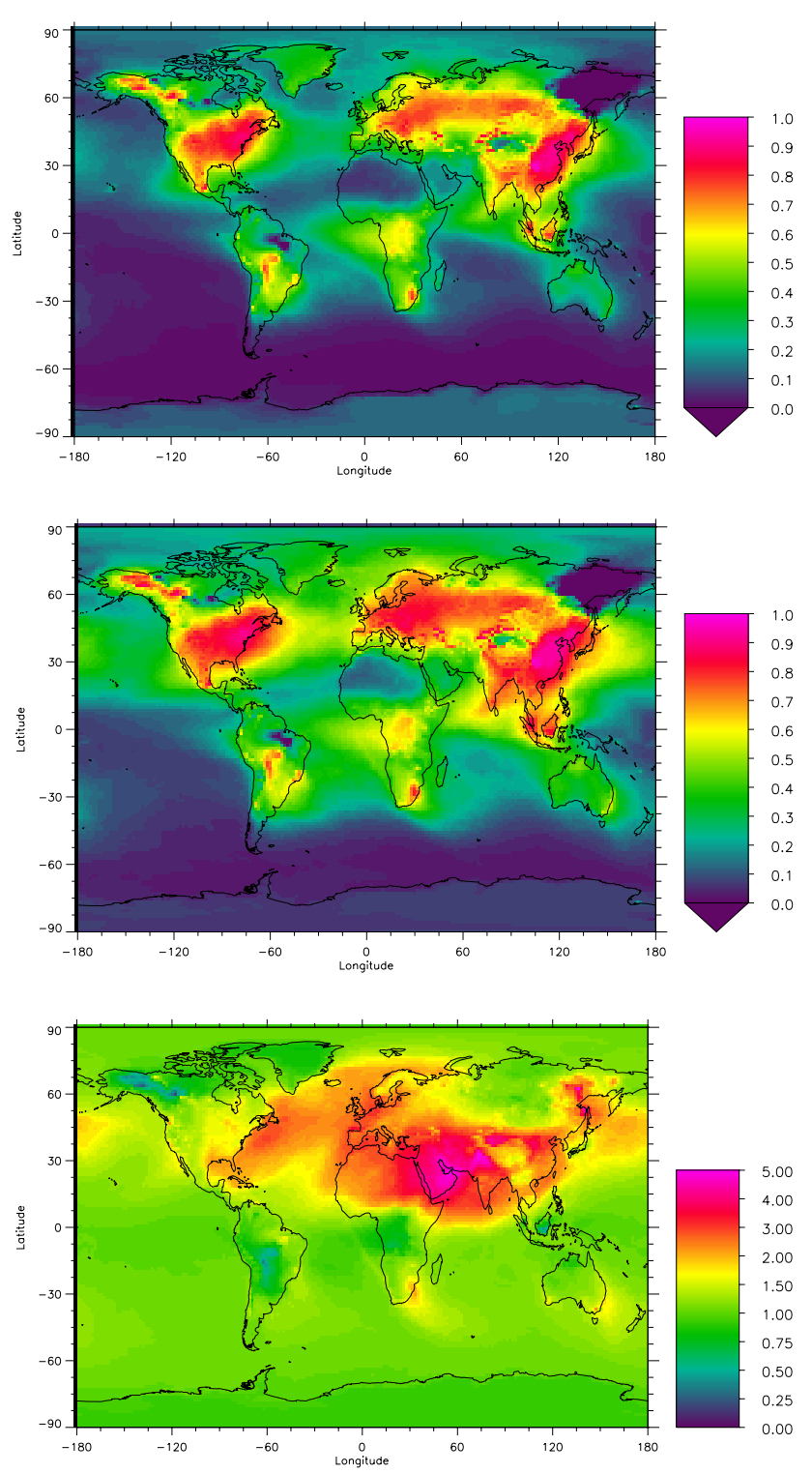

Fig. 18. Anthropogenic AOD fraction of total AOD (upper), anthropogenic AOD fraction of fine mode AOD (middle), and change in the fraction of secondary aerosols (sulphate, nitrate, and SOA) over the industrial era. (lower)

in Fig. 18. The global mean fraction is estimated to be $24 \%$, ranging from close to zero over the Southern Hemisphere ocean to 95\% in South East Asia. Figure 18 also shows the anthropogenic fraction of fine mode particles. The anthropogenic fraction of fine mode particles is higher than the anthropogenic fraction of total aerosols since the importance of sea salt and mineral dust is much smaller. With the inclusion of explicit calculation of secondary components of nitrate and organic aerosols, and their change since pre-industrial time, the total anthropogenic fraction has increased.

\subsubsection{Anthropogenic AOD}

Figure 19 shows the anthropogenic AOD of five aerosol compounds. The sulphate is the dominating aerosol compound in terms of anthropogenic AOD. Similar to Fig. 18, Fig. 19 shows that anthropogenic AOD is mostly localized to North America, Europe, East Asia, and biomass burning regions in South-America and Africa.

\subsubsection{Fraction of secondary aerosols}

To illustrate further the compositional change of atmospheric aerosols that has occurred over the industrial era, the fraction of AOD from the secondary aerosol components (sulphate, nitrate, and SOA) to the total AOD is shown in Fig. 18. The fraction of secondary aerosols has substantially increased since pre-industrial time and for large part of the Northern Hemisphere it has more than doubled.

\subsubsection{Change in single scattering albedo}

The present day single scattering albedo is compared to measurements in Sect. 3.4, with both observations and model results showing substantial regional variations. The global mean single scattering albedo is simulated to be 0.97 assuming $\mathrm{BC}$ to be externally mixed, with values over land typically being much lower than this and over remote oceanic region close to unity. The Oslo CTM2 predicts that the single scattering albedo has decreased due to anthropogenic activity. The fraction of absorbing AOD is simulated to be doubled. The reduction in the single scattering albedo can be expected from emission data of $\mathrm{BC}$, the dominant contributor to atmospheric aerosol absorption, since it has increased by more than a factor of five over the industrial era (Dentener et al., 2006).

\section{Radiative forcing}

(IPCC, 2007) provided RF for six aerosol components and the total RF of the direct aerosol effect. The RF of the total direct aerosol effect had a best estimate of $-0.5 \mathrm{Wm}^{-2}$ with a range from -0.1 to $-0.9 \mathrm{Wm}^{-2}$. This estimate was based on global aerosol model calculations and observational based estimates. We have calculated RF for five aerosol components including sulphate, $\mathrm{BC}$ from fossil and biofuel, OC from fossil and biofuel as well as SOA, biomass burning (BB) (combination of OC and $\mathrm{BC}$ ), and nitrate. This is the same as in (IPCC, 2007) except that we do not provide any estimate of RF for mineral dust. 

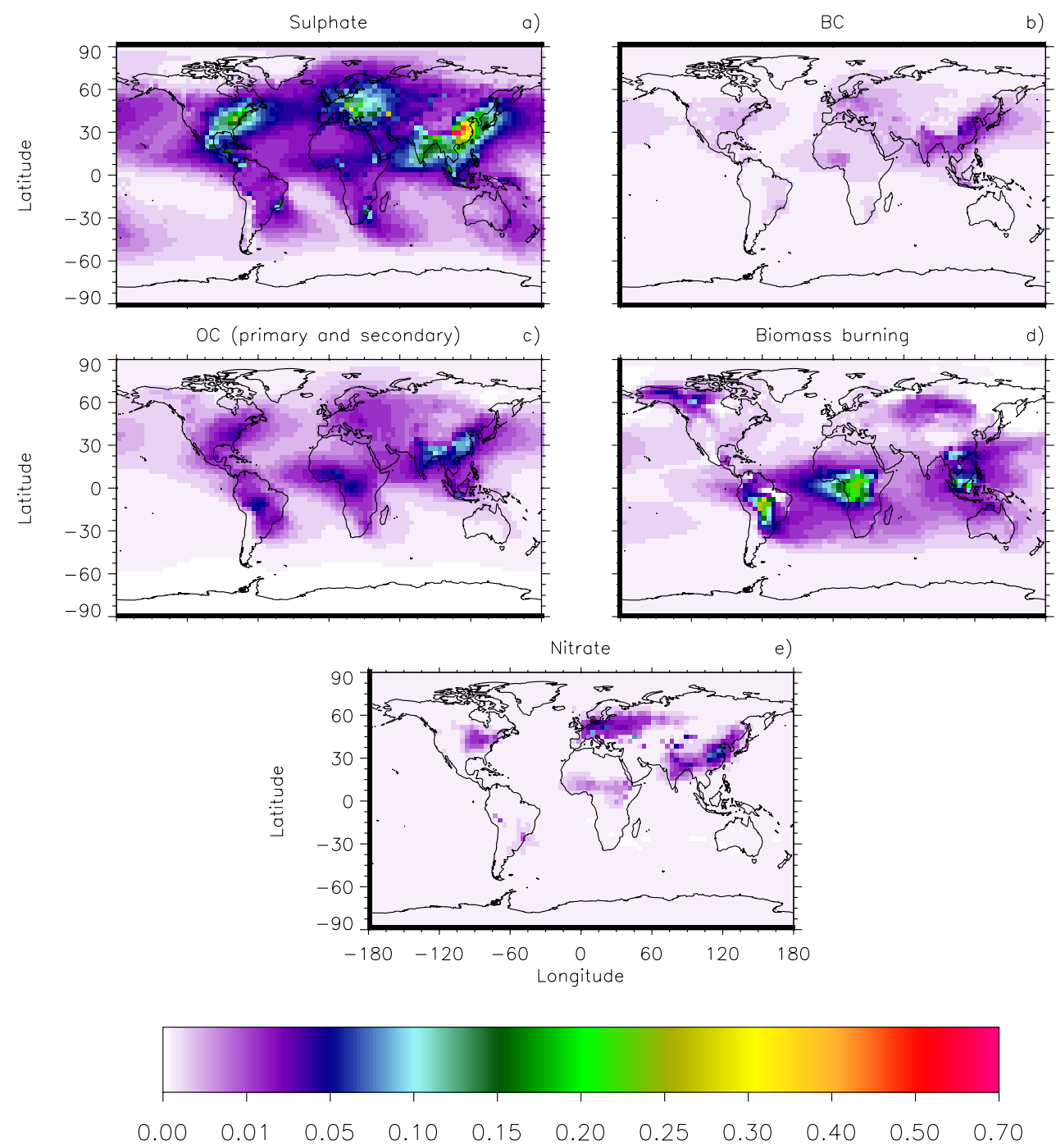

Fig. 19. Anthropogenic AOD of various aerosol components, sulphate (a), BC from fossil and biofuel (b), primary and secondary OC from fossil and biofuel (c), biomass burning aerosols (d), nitrate (e).

\subsection{Standard simulations}

The annual mean geographical distributions of the RF for six aerosol components are shown in Fig. 20. The global and annual mean burden and AOD as well as RF and normalized RF are shown in Table 1. The RF of the total direct aerosol effect consists of several positive and negative RF as shown in Fig. 21, where a comparison with earlier IPCC estimates and Oslo CTM2 results are provided. Note that in Table 1 the RF due to SOA is given separately, whereas in Fig. 21 it is incorporated into the RF of BB aerosols and RF due to OC from use of fossil fuel (FF) and biofuel (BF). Due to the importance of clouds for the radiative forcing we have included the total cloud cover in Fig. 22.

The geographical distribution in Fig. 20 shows that sulphate is the dominant negative RF component and $\mathrm{BC}$ the dominant warming compound. $\mathrm{OC}$ also has a significant cooling effect, and is divided into primary and secondary components, while the RF due to nitrate is rather weak, and $\mathrm{BB}$ aerosols have both positive and negative RF. The RF due to sulphate has the pattern as shown in several previous studies with maxima over south-east Asia, Europe, USA (Adams et al., 2001; Boucher and Pham, 2002; Charlson et al., 1991; Haywood and Shine, 1995; Liao et al., 2004; Myhre et al., 2004; Takemura et al., 2002). The pattern of sulphate also resembles that of other aerosol components with large industrialized emissions. Land and coastal regions have the strongest RF and only between 0 and 40 degree north is the $\mathrm{RF}$ over ocean significant. The RF due to sulphate is stronger in this work than earlier versions of the model. This difference is partly because of a somewhat higher burden of close to $15 \%$, and the higher spatial resolution that strengthens the 

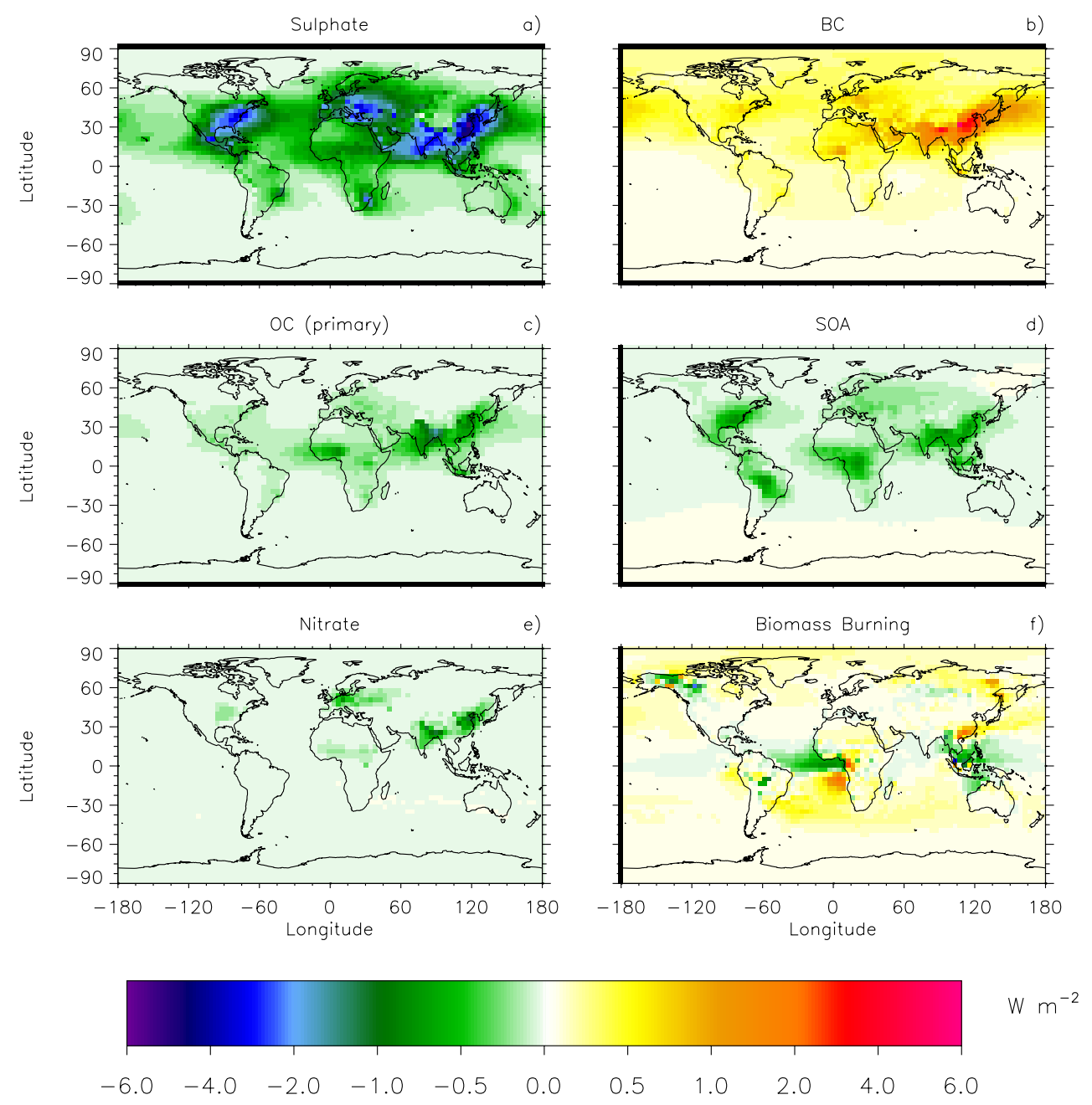

Fig. 20. Radiative forcing $\left(\mathrm{W} \mathrm{m}^{-2}\right.$ ) due to anthropogenic aerosols, (a) sulphate, (b) BC (fossil and bio-fuel), (c) primary OC (fossil and bio-fuel), (d) secondary organic aerosols (SOA), (e) nitrate, (f) primary biomass burning aerosols.

water uptake, resulting in a $10 \%$ higher RF compared to simulations using T42 (2.8 degree) resolution which have been run earlier. This is in line with previous results of investigating the importance of relative humidity (Myhre et al., 2002, 2004). This higher water uptake is reflected in the higher normalized RF with respect to burden compared to that reported in (Schulz et al., 2006).

The RF due to $\mathrm{BC}$ from fossil and bio - fuel is calculated to be $0.26 \mathrm{Wm}^{-2}$ in the base case (externally mixed). This is a stronger BC RF than simulated by any of the models in the AeroCom exercise (Schulz et al., 2006), but weaker than some of the estimates using the GISS model (Hansen et al., 2005; Liao and Seinfeld, 2005). The main reason for the enhanced RF in this versions of the model, is the increased burden of $\mathrm{BC}$ of about $50 \%$. Another reason is that the RF of $\mathrm{BC}$ is enhanced is that all other main aerosol species are included in the radiative transfer calculations. In particular, the scattering aerosols are important as they enhance the absorption due to increased diffuse solar radiation (Stier et al., 2006) leading to an increase in the RF by close to $10 \%$. Bond and Bergstrom (2006) have made a critical assessment of the factors that influence the optical properties of BC. In the base calculations we use a density of $1.0 \mathrm{~g} / \mathrm{cm}^{3}$, a size distribution with a geometric radius of $0.0118 \mu \mathrm{m}$ and standard deviation of 2.0 , and a refractive index of $1.75-0.44 \mathrm{i}$ at $550 \mathrm{~nm}$. An additional simulation is performed with a size distribution of geometric radius of $0.04 \mu \mathrm{m}$ and standard deviation of 1.5 , a density of $1.5 \mathrm{~g} / \mathrm{cm}^{3}$ and a refractive index $1.85-0.71 \mathrm{i}$ at $550 \mathrm{~nm}$. Only the density is lower than recommendations $\left(1.7-1.9 \mathrm{~g} / \mathrm{cm}^{3}\right)$, but this is to get the recommended absorption coefficient of $7.5 \mathrm{~m}^{2} / \mathrm{g}$ (Bond and Bergstrom, 2006). The RF for the simulation with updated $\mathrm{BC}$ optical properties was $3.5 \%$ different compared to the standard case. This small effect is due to the compensation of the density and refractive index of the recommended values in Bond and Bergstrom (2006) and the values used in the 
Table 1. Anthropogenic burden, $A O D$ at $550 \mathrm{~nm}$, radiative forcing (RF) due to the direct aerosol effect, and normalized RF (both with respect to anthropogenic burden and AOD).

\begin{tabular}{|c|c|c|c|c|c|c|}
\hline $\begin{array}{c}\text { Aerosol } \\
\text { component }\end{array}$ & $\begin{array}{c}\text { Burden } \\
\left(\mathrm{mg} \mathrm{m}^{-2}\right)\end{array}$ & $\begin{array}{c}\text { AOD } \\
(550 \mathrm{~nm})\end{array}$ & $\begin{array}{c}\text { AOD Ant } \\
\text { fraction }(\%)\end{array}$ & $\begin{array}{c}\mathbf{R F} \\
\left(\mathbf{W} \mathbf{m}^{-2}\right)\end{array}$ & $\begin{array}{l}\text { Normalized RF } \\
\quad\left(\mathrm{Wg}^{-1}\right)\end{array}$ & $\begin{array}{l}\text { Normalized RF } \\
\qquad\left(\mathrm{W} \mathrm{m}^{-2}\right)\end{array}$ \\
\hline Sulphate & 1.94 & 0.024 & 50 & -0.44 & -227 & -19 \\
\hline $\mathrm{BC}(\mathrm{FF}+\mathrm{BF})$ & 0.19 & $0.0018(0.0024)$ & 91 & $0.26(0.33)$ & $1326(1693)$ & 143 (139) \\
\hline $\mathrm{OC}(\mathrm{FF}+\mathrm{BF})$ & 0.33 & 0.0034 & 87 & -0.09 & -273 & -27 \\
\hline OC SOA* & 0.31 & 0.0035 & 38 & -0.09 & -286 & -26 \\
\hline Biomass burning & $0.74^{+}$ & 0.011 & 59 & 0.07 & 95 & 7 \\
\hline Nitrate & 0.11 & 0.0012 & 98 & $-\mathbf{0 . 0 2 3}$ & -208 & -19 \\
\hline Total & 3.63 & $0.044(0.045)$ & $41^{\&}\left(41^{\&}\right)$ & $-0.35(-0.28)$ & $-96(-77)$ & $-8(-6)$ \\
\hline
\end{tabular}

${ }^{*}$ Part of it is from biomass burning; ${ }^{+} 87 \%$ is OC; ${ }^{\&}$ The anthropogenic fraction for the total aerosol refer to fine mode aerosols; Numbers in parentheses for $\mathrm{BC}$ are for the enhanced absorption associated with internal mixing.

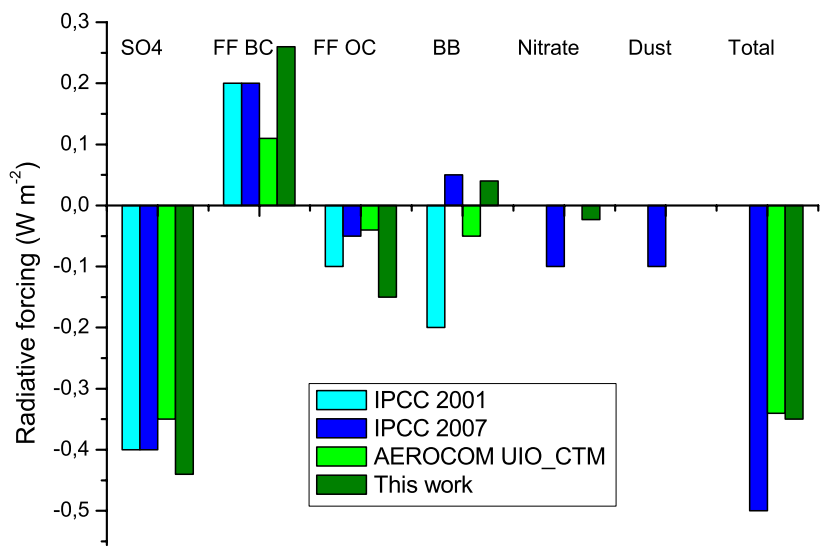

Fig. 21. RF estimates for various aerosol components from this work, earlier Oslo CTM2 results (AEROCOM UIO_CTM), and IPCC estimates.

standard case. This can also been seen in the absorption coefficient for the standard case of $7.3 \mathrm{~m}^{2} / \mathrm{g}$, which is also close to the recommended value.

Several studies have shown that the absorption of BC is enhanced if it is mixed with other particles (internal mixture) rather than separated from other particles (external mixture) (Bond et al., 2006; Fuller et al., 1999; Haywood and Shine, 1995). In the atmosphere BC is observed to be in a combination of internal and external mixture (Cheng et al., 2006; Hara et al., 2003; Mallet et al., 2004; Wentzel et al., 2003). Increasing the absorption for hydrophilic BC particles by $50 \%$ (but with no change for the hydrophobic BC particles) has been suggested as a simple method to account for the internal mixture (Bond et al., 2006). Using this approach the $\mathrm{RF}$ for BC increases to $0.33 \mathrm{Wm}^{-2}$ from $0.26 \mathrm{Wm}^{-2}$ in the standard simulation (a $28 \%$ increase). This type of internal

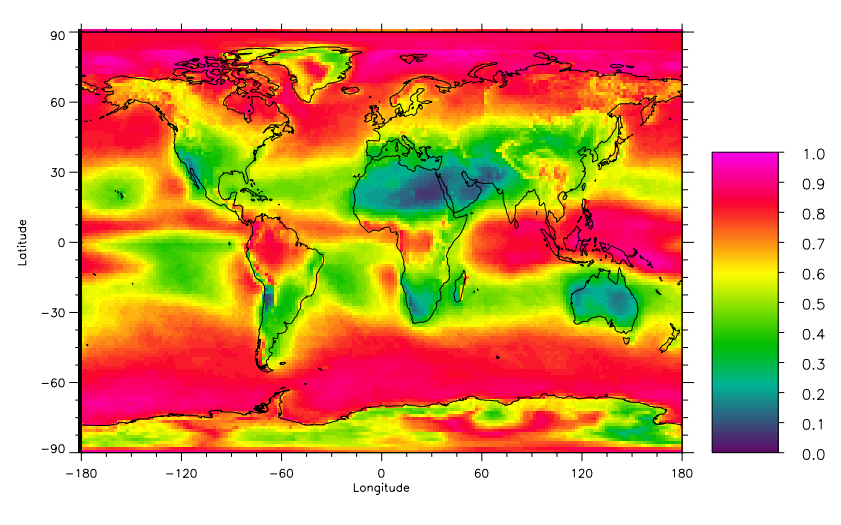

Fig. 22. Annual mean total cloud cover used in the radiative forcing calculations.

mixing represents a coating on the $\mathrm{BC}$ particles and increase the RF less than a homogeneous internal mixture assumed in previous RF calculations (Bond et al., 2006).

The understanding of the atmospheric OC particles has increased significantly over the last 5 years; however, the scientific knowledge is still not complete (Andreae and Gelencser, 2006; Fuzzi et al., 2006; Gelencser et al., 2007; Kanakidou et al., 2005; Robinson et al., 2007). Recent studies indicate that SOA constitutes a significant fraction of the OC, in particular during summer (Crosier et al., 2007; Gelencser et al., 2007). The estimate for RF of OC associated with fossil fuel and biofuel calculated in this study $\left(-0.15 \mathrm{Wm}^{-2}\right)$ is substantially stronger than in IPCC AR4 (Forster et al., 2007) $\left(-0.05 \mathrm{Wm}^{-2}\right)$ and for the Oslo CTM2 $\left(-0.04 \mathrm{Wm}^{-2}\right)$ in the AeroCom exercise (Schulz et al., 2006). This difference arises because anthropogenic SOA is included in the calculations. The magnitude of the RF of SOA is identical in the 
global mean to the RF of primary OC from fossil and biofuel. SOA was included in the AeroCom exercise in a very simplified way - as primary OC, but all of it was assumed to be natural and thus the anthropogenic influence on the SOA concentration was neglected. Here, the anthropogenic SOA arises from the emission of anthropogenic SOA precursors, increased aerosol amount for SOA to partition to, and increased atmospheric oxidation capacity (Hoyle et al., 2008) Based on simulations in Hoyle et al. (2008) we estimate that $1 / 3$ of the SOA is associated with biomass burning aerosols and their precursors and the rest is associated with fossil and biofuel emissions. The RF due to primary OC is also strengthened compared to that in (Schulz et al., 2006) due to a combination of larger burden and an increased ratio of OM/OC more in line with observations (Polidori et al., 2008; Turpin and Lim, 2001). It has been suggested that some of the OC contains an absorbing fraction (Andreae and Gelencser, 2006; Lukacs et al., 2007), especially at short wavelengths (Jacobson, 1999; Sun et al., 2007), but this is not investigated further here.

The RF due to nitrate is estimated in this study to be weak, which is consistent with a previous study using the same model and approach (Myhre et al., 2006). The RF is restricted to some localized land regions where there is sufficient ammonium to form ammonium-nitrate. Since ammonium-nitrate is dependent on several other aerosol components and their precursors as well as temperature, the modelling is more complicated than other inorganic compounds (Feng and Penner, 2007; Martin et al., 2004; Metzger et al., 2002; Morino et al., 2006; Myhre et al., 2006). The surface concentration of ammonium-nitrate does not necessary give a lot of information about the concentration in the lower troposphere since at the surface ammonia is rather high and the sulphate concentration often is somewhat lower at the surface compared to slightly higher in the typical aerosol layers. Another important aspect is that over the ocean (also close to industrialized regions), fine mode nitrate is close to negligible in observations (see Sect. 3.1.2) and the coarse mode nitrate is significant. The Oslo CTM2 reproduces this feature. The RF of nitrate in this work of $-0.023 \mathrm{Wm}^{-2}$ is weaker than many other studies, but the range is wide (Adams et al., 2001; Bauer et al., 2007; Jacobson, 2001; Liao and Seinfeld, 2005). During the aerosol campaign ADRIEX in August and September 2004 located near Venice in Italy it was found that nitrate was a major constituent of the aerosol composition (Crosier et al., 2007). The Oslo CTM2 reproduced the main pattern of the observed nitrate; however, the equilibrium constant for ammonium nitrate was altered compared to in this study which increased the nitrate abundance (Myhre et al., 2009). Applying the equilibrium constant for ammonium nitrate used during ADRIEX for global simulations increased the nitrate RF by slightly more than $50 \%$ for August and September. Such an increase in the nitrate RF would lead to an annual mean value of $-0.035 \mathrm{Wm}^{-2}$.
Biomass burning in Africa and South America is often associated with higher AOD and lower single scattering albedo values than in many other regions and large aerosol campaigns have investigated this in more detail (Kaufman et al., 1998; Swap et al., 2003). The global and annual mean RF estimate in this study is slightly positive with a large regional variation in the magnitude of the RF. In addition, the sign varies depending on the surface reflectance and cloud cover. The RF of the primary BB aerosols is estimated to be $0.07 \mathrm{Wm}^{-2}$ and that of secondary $\mathrm{BB}$ aerosols to be $-0.03 \mathrm{Wm}^{-2}$. A significant fraction of the $\mathrm{BB}$ aerosols is transported at rather high altitude in the tropical areas (Haywood et al., 2003) and may affect the cloud cover. The climate impact of this is uncertain (Johnson et al., 2004; Penner et al., 2003). Of the aerosol components shown in Fig. 20 it is only the BB aerosol for which the RF varies in sign in the geographical distribution. For the total RF of the direct aerosol effect; however, the sign changes at around 40 degree with cooling effect dominating (Fig. 21a).

Normalized RF is shown in Table 1 with respect to mass and AOD. The magnitude of the normalized RF is particularly large for $\mathrm{BC}$, illustrating the high radiative efficiency for atmospheric BC, which is in accordance with previous studies (Schulz et al., 2006). The normalized RF with respect to mass is stronger for OC than sulphate and nitrate, partly due to the larger mass associated with this fraction (elements such as $\mathrm{O}$ and $\mathrm{H}$ constitute a larger mass increase for $\mathrm{OC}$ than ammonium for sulphate and nitrate). Further, the spatial distribution of OC is generally at lower latitudes than sulphate and nitrate. In terms of the normalized RF with respect to AOD the values for sulphate and nitrate are equal, whereas OC has stronger values. The latter can again be explained by the spatial distribution, but the less water uptake for $\mathrm{OC}$ and thus the smaller particle size that results in smaller asymmetry factor might contribute.

The radiative effect of the aerosol depends on the scattering and absorbing constituents in the atmosphere and is thus dependent on the other aerosol components. An example of this is that scattering aerosols enhance the absorption of $\mathrm{BC}$ by $10 \%$, from $0.23 \mathrm{Wm}^{-2}$ to $0.26 \mathrm{Wm}^{-2}$. Adding the numbers in Table 1 results in a total RF of $-0.32 \mathrm{Wm}^{-2}$. However, the all sky RF of anthropogenic aerosols is simulated to be $-0.35 \mathrm{Wm}^{-2}$, illustrating the non-linear RF due to enhanced absorption from $\mathrm{BC}$ because of the scattering aerosols.

The RF of the direct aerosol effect of anthropogenic particles under clear sky condition is $-1.07 \mathrm{Wm}^{-2}$. In the AeroCom exercise Oslo CTM2 was one of three models with a negative global mean cloudy sky RF (Schulz et al., 2006). In this study the global mean cloudy sky RF (difference between all sky RF and RF in the regions absent with clouds) is slightly positive $\left(0.02 \mathrm{Wm}^{-2}\right)$. However, there is a significant geographical variation in the cloud sky RF (not shown) with general negative values close to industrialized source regions and positive values away from these regions. The 
most positive cloudy sky RF is simulated over the ocean at the west coast of Southern Africa and for smaller regions in South East Asia, whereas the most negative values are found at coastal regions near India and Malaysia. The distinction between clear and cloudy sky in the atmosphere can sometimes be imprecise (Charlson et al., 2007).

The surface radiative effect of the total direct aerosol effect simulated in this study is $-1.86 \mathrm{Wm}^{-2}$ for all sky and -2.59 for clear sky $\mathrm{Wm}^{-2}$.

\subsection{Additional simulations}

Sensitivity calculations were performed to investigate the robustness of the RF results. The additional simulations were mainly performed based on the model performance against the observations in Sect. 3.

Figure 10 shows differences between the AOD from the model and satellite data in particular at high latitudes as well as in other regions (see further discussion in the text and comparison with AERONET data). We have scaled the AOD from the mean of MODIS (Collection 5) data and MISR to the AOD from the model and adopted this in a RF estimate. The resulting RF is enhanced in some of the industrialized regions (especially in south East Asia) and particularly at high latitudes (Fig. 23). However, globally these enhancements cancel each other to a large degree so that the global mean is almost unchanged.

The underestimation of AOD from the Oslo CTM2 model over parts of Asia is consistent in comparison with AERONET and satellite data. Applying the scaling with the satellite data described above restricted to the region $60 \mathrm{E}-180 \mathrm{E}$ and $0-40 \mathrm{~N}$ strengthens the RF slightly to $-0.37 \mathrm{Wm}^{-2}(6 \%)$.

The comparison of SSA between the model and AERONET in Figs. 11 and 12 showed some variations but no systematic trends. However, the mean of the AERONET data was slightly lower than the values from the model (see Sect. 3.4). In a simulation the SSA is reduced by 0.03 , which is a substantially larger magnitude than mean deviations in the comparison of SSA with AERONET data. The resulting $\mathrm{RF}$ is significantly weakened to $-0.16 \mathrm{Wm}^{-2}$.

\section{Summary}

The combination of global aerosol models and increasing number of aerosol observations has improved our understanding and reduced the uncertainty in the estimates of the direct aerosol effect. This improvement is well documented in the advancement of the direct aerosol effect in the recent IPCC reports (Forster et al., 2007). The progression can be seen in the number of chemical species included both in the observations and in the global aerosol models.

In this study we go beyond the complexity in the standard global aerosol models (Schulz et al., 2006; Textor et

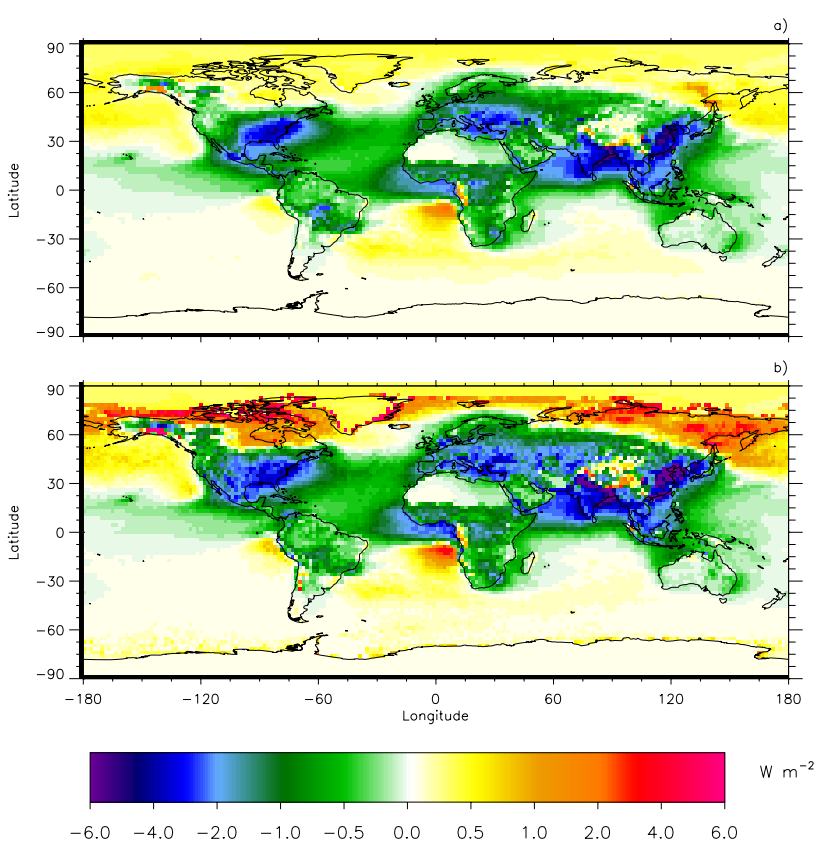

Fig. 23. RF from the total direct aerosol effect, from the Oslo CTM2 (a) RF where the AOD from a combination of MODIS and MISR is scaled to the Oslo CTM2 AOD (b).

al., 2006) with respect to spatial resolution and the number of chemical components which are incorporated. The main results of the comparison of the global aerosol model with measurements for the year 2004 are

- Compared to observations near the surface, either on land or ocean, the aerosol model performs well.

- The model reproduces regional differences in AOD at least as well as satellite data in comparison with AERONET data

- Given the uncertainties and complexities in the observations, the modelled SSA is in reasonable agreement with AERONET measurements

- The main features of annual values and seasonal trends are reproduced to within about $10-20 \%$ of the AERONET data, except in parts of South-East Asia and North-Western Africa, likely in both regions to be linked to inaccuracies in assumptions or parameterization of emissions.

To gain confidence into the aerosol modelling the ability to reproduce the daily variability is of high importance

- The Oslo CTM2 reproduces the majority of the daily variability in $\mathrm{AOD}$ at most locations

- Close to regions with variability in the non-wind driven emissions (e.g. biomass burning aerosols) the daily variability is not as well reproduced. 
- In some industrialized regions such as at Ispra in the Po valley, having complex chemical composition, often with OC dominating, the daily variability is less well captured.

In this study we find some key results for anthropogenic aerosol changes and their radiative effect

- A large fraction of the modelled OC in the atmosphere is anthropogenic SOA, partly due to emissions of anthropogenic SOA precursors but more importantly due to increases in aerosol content and atmospheric oxidation capacity over the industrial era.

- We estimate a larger anthropogenic fraction of aerosols and a larger fraction of secondary aerosols than in previous global aerosol model simulations, as a result of implementing anthropogenic SOA and nitrate in the Oslo CTM2.

- The Oslo CTM2 is able to calculate the strong radiative effect of aerosols over oceans in clear sky conditions in accordance with the satellite derived estimate, even though there are some variations between estimates of the latter.

- The RF due to carbonaceous aerosols from fossil fuel and biomass burning is strengthened in these new simulations compared to previous estimates with the OsloCTM2 model.

- Inclusion of internal mixture of BC as a coating on hydrophilic $\mathrm{BC}$ aerosols strengthen the RF compared to external mixture, but to a much smaller degree than earlier studies with assumption of homogeneous internal mixture

- With scattering and absorbing aerosol constituents included in the models, non-linearity in the RF arises. The magnitude of this is estimated at $10 \%$

- The RF due to the total direct aerosol effect is calculated to be $-0.35 \mathrm{Wm}^{-2}$ in the Oslo CTM2 model

Acknowledgements. We thank the principal investigators and their staff for establishing and maintaining the 180 AERONET sites used in this study. We also thank those responsible for the observational ground based networks EMEP, EANET, and IMPROVE, for permission to use the data. We appreciate the work made for providing emission data from biomass burning data through GFED. The work has received support from the Norwegian research Council's program for supercomputing through a grant of computer time. We thank the NASA Langley Atmospheric Sciences Data Center and the MISR Team for providing and distributing the MISR data.

Edited by: W. Conant

\section{References}

Abdou, W. A., Diner, D. J., Martonchik, J. V., et al.: Comparison of coincident Multiangle Imaging Spectroradiometer and Moderate Resolution Imaging Spectroradiometer aerosol optical depths over land and ocean scenes containing Aerosol Robotic Network sites, J. Geophys. Res., 110(D10), D10S07, 11967-11976, 2005.

Adams, P. J., Seinfeld, J. H., Koch, D., Mickley, L., and Jacob, D.: General circulation model assessment of direct radiative forcing by the sulfate-nitrate-ammonium-water inorganic aerosol system, J. Geophys. Res., 106(D1), 1097-1111, 2001.

Alpert, P., Kishcha, P., Kaufman, Y. J., and Schwarzbard, R.: Global dimming or local dimming?: Effect of urbanization on sunlight availability, Geophys. Res. Lett., 32(17), L17802, 2005.

Andreae, M. O. and Gelencser, A.: Black carbon or brown carbon? The nature of light-absorbing carbonaceous aerosols, Atmos. Chem. Phys., 6, 3131-3148, 2006,

http://www.atmos-chem-phys.net/6/3131/2006/.

Bauer, S. E., Koch, D., Unger, N., Metzger, S. M., Shindell, D. T., and Streets, D. G.: Nitrate aerosols today and in 2030: a global simulation including aerosols and tropospheric ozone, Atmos. Chem. Phys., 7, 5043-5059, 2007,

http://www.atmos-chem-phys.net/7/5043/2007/.

Bellouin, N., Boucher, O., Haywood, J. and Reddy, M. S.: Global estimate of aerosol direct radiative forcing from satellite measurements, Nature, 438, 1138-1141, 2005.

Berglen, T. F., Berntsen, T. K., Isaksen, I. S. A., and Sundet, J. K.: A global model of the coupled sulfur/oxidant chemistry in the troposphere: The sulfur cycle, J. Geophys. Res., 109(D19), D19310, doi:10.1029/2003JD003948, 2004.

Berntsen, T., Fuglestvedt, J., Myhre, G., Stordal, F., and Berglen, T. F.: Abatement of greenhouse gases: Does location matter?, Climatic Change, 74(4), 377-411, 2006.

Bond, T. C. and Bergstrom, R. W.: Light absorption by carbonaceous particles: An investigative review, Aerosol Sci. Technol., 40(1), 27-67, 2006.

Bond, T. C., Habib, G., and Bergstrom, R. W.: Limitations in the enhancement of visible light absorption due to mixing state, J. Geophys. Res., 111(D20), D20211, doi:10.1029/2006JD007315, 2006.

Bond, T. C., Streets, D. G., Yarber, K. F., et al.: A technologybased global inventory of black and organic carbon emissions from combustion, J. Geophys. Res., 109(D14), D14203, doi:10.1029/2003JD003697, 2004.

Boucher, O. and Pham, M.: History of sulfate aerosol radiative forcings, Geophys. Res. Lett., 29(9), 1308, doi:10.1029/2001GL014048, 2002.

Boucher, O. and Tanré, D.: Estimation of the aerosol perturbation to the Earth's radiative budget over oceans using POLDER satellite aerosol retrievals, Geophys. Res. Lett., 27(8), 1103-1106, 2000.

Charlson, R. J., Ackerman, A. S., Bender, F. A. M., Anderson, T. L., and Liu, Z.: On the climate forcing consequences of the albedo continuum between cloudy and clear air, Tellus, 59(4), 715-727, 2007.

Charlson, R. J., Langner, J., Rodhe, H., Leovy, C. B., and Warren, S. G.: Perturbation of the Northern-Hemisphere Radiative Balance by Backscattering from Anthropogenic Sulfate Aerosols, Tellus A, 43(4), 152-163, 1991. 
Cheng, Y. F., Eichler, H., Wiedensohler, A., et al.: Mixing state of elemental carbon and non-light-absorbing aerosol components derived from in situ particle optical properties at Xinken in Pearl River Delta of China, J. Geophys. Res., 111(D20), D20204, doi:10.1029/2005JD006929, 2006.

Christopher, S. A. and Zhang, J. L.: Shortwave aerosol radiative forcing from MODIS and CERES observations over the oceans, Geophys. Res. Lett., 29(18), 1859, doi:10.1029/2002GL014803, 2002.

Chung, C. E., Ramanathan, V., Kim, D., and Podgorny, I. A.: Global anthropogenic aerosol direct forcing derived from satellite and ground-based observations, J. Geophys. Res., 110(D24), D24207, doi:10.1029/2005JD006356, 2005.

Crosier, J., Allan, J. D., Coe, H., Bower, K. N., Formenti, P., et al.: Chemical composition of summertime aerosol in the Po Valley (Italy), northern Adriatic and Black Sea, Q. J. R. Meteorol. Soc., 133, 61-75, 2007.

Dentener, F., Kinne, S., Bond, T., Boucher, O., Cofala, J., Generoso, S., Ginoux, P., Gong, S., Hoelzemann, J. J., Ito, A., Marelli, L., Penner, J. E., Putaud, J.-P., Textor, C., Schulz, M., van der Werf, G. R., and Wilson, J.: Emissions of primary aerosol and precursor gases in the years 2000 and 1750 prescribed data-sets for AeroCom, Atmos. Chem. Phys., 6, 4321-4344, 2006, http://www.atmos-chem-phys.net/6/4321/2006/.

Fagerli, H. and Aas, W.: Trends of nitrogen in air and precipitation: Model results and observations at EMEP sites in Europe, 19802003, Environ. Pollut., 154, 448-461, 2008.

Feng, Y. and Penner, J. E.: Global modeling of nitrate and ammonium: Interaction of aerosols and tropospheric chemistry, J. Geophys. Res., 112(D1), D01304, doi:10.1029/2005JD006404, 2007.

Formenti, P., Elbert, W., Maenhaut, W., Haywood, J., Osborne, S., et al.: Inorganic and carbonaceous aerosols during the Southern African Regional Science Initiative (SAFARI 2000) experiment: Chemical characteristics, physical properties, and emission data for smoke from African biomass burning, J. Geophys. Res., 108(D13), 8488, 2003.

Forster, P., Ramaswamy, V., Artaxo, P., Berntsen, T., Betts, R., et al.: Changes in atmospheric constituents and in radiative forcing, in: Climate change 2007: The physical science basis. Contribution of Working Group I to the Fourth Assessment Report of the Intergovernmental Panel on Climate Change Cambridge University Press, edited by: Solomon, S., Qin, D., Manning, M., Chen, Z., Marquis, M., et al., United Kingdom and New York, NY, USA, 2007.

Fuller, K. A., Malm, W. C., and Kreidenweis, S. M.: Effects of mixing on extinction by carbonaceous particles, J. Geophys. Res., 104(D13), 15941-15954, 1999.

Fuzzi, S., Andreae, M. O., Huebert, B. J., Kulmala, M., Bond, T. C., Boy, M., Doherty, S. J., Guenther, A., Kanakidou, M., Kawamura, K., Kerminen, V.-M., Lohmann, U., Russell, L. M., and Pschl, U.: Critical assessment of the current state of scientific knowledge, terminology, and research needs concerning the role of organic aerosols in the atmosphere, climate, and global change, Atmos. Chem. Phys., 6, 2017-2038, 2006, http://www.atmos-chem-phys.net/6/2017/2006/.

Gelencser, A.: Carbonaceous aerosol, Springer, Dordrecht, 30 pp., 2004.
Gelencser, A., May, B., Simpson, D., Sanchez-Ochoa, A., KasperGiebl, A., et al.: Source apportionment of $\mathrm{PM}_{2.5}$ organic aerosol over Europe: Primary/secondary, natural/anthropogenic, and fossil/biogenic origin, J. Geophys. Res., 112(D23), D23S04, doi:10.1029/2006JD008094, 2007.

Graber, E. R. and Rudich, Y.: Atmospheric HULIS: How humiclike are they? A comprehensive and critical review, Atmos. Chem. Phys., 6, 729-753, 2006, http://www.atmos-chem-phys.net/6/729/2006/.

Grini, A., Myhre, G., Sundet, J. K., and Isaksen, I. S. A.: Modeling the annual cycle of sea salt in the global 3D model Oslo CTM2: Concentrations, fluxes, and radiative impact, J. Climate, 15(13), 1717-1730, 2002.

Grini, A., Myhre, G., Zender, C. S., and Isaksen, I. S. A.: Model simulations of dust sources and transport in the global atmosphere: Effects of soil erodibility and wind speed variability, J. Geophys. Res., 110(D2), D02205, doi:10.1029/2004JD005037, 2005.

Hansen, J., Sato, M., and Ruedy, R.: Radiative forcing and climate response, J. Geophys. Res., 102(D6), 6831-6864, 1997.

Hansen, J., Sato, M., Ruedy, R., Nazarenko, L., Lacis, A., et al.: Efficacy of climate forcings, J. Geophys. Res., 110(D18), D18104, doi:10.1029/2005JD005776, 2005.

Hara, K., Yamagata, S., Yamanouchi, T., Sato, K., Herber, A., et al.: Mixing states of individual aerosol particles in spring Arctic troposphere during ASTAR 2000 campaign, J. Geophys. Res., 108(D7), 4209, doi:10.1029/2002JD002513, 2003.

Haywood, J. M., Pelon, J. Formenti, P., et al.: Overview of the Dust and Biomass-burning Experiment and African Monsoon Multidisciplinary Analysis Special Observating Period-0, J. Geophys. Res., 113, D00C17, doi:10.1029/2008JD010077, 2008.

Haywood, J. M., Osborne, S. R., Francis, P. N., Keil, A., Formenti, P., et al.: The mean physical and optical properties of regional haze dominated by biomass burning aerosol measured from the C-130 aircraft during SAFARI 2000, J. Geophys. Res., 108(D13), 8473, doi:10.1029/2002JD002226, 2003.

Haywood, J. M., Ramaswamy, V., and Donner, L. J.: A limitedarea-model case study of the effects of sub-grid scale variations in relative humidity and cloud upon the direct radiative forcing of sulfate aerosol, Geophys. Res. Lett., 24(2), 143-146, 1997.

Haywood, J. M. and Shine, K. P.: The effect of anthropogenic sulfate and soot aerosol on the clear-sky planetary radiation budget, Geophys. Res. Lett., 22(5), 603-606, 1995.

Haywood, J. M. and Shine, K. P.: Multi-spectral calculations of the direct radiative forcing of tropospheric sulphate and soot aerosols using a column model, Q. J. R. Meteorol. Soc., 123(543), 19071930, 1997.

Holben, B. N., Eck, T. F., Slutsker, I., Tanre, D., Buis, J. P., et al.: AERONET - A federated instrument network and data archive for aerosol characterization, Remote Sens. Environ., 66(1), 1$16,1998$.

Hoyle, C. R., Berntsen, T., Myhre, G., and Isaksen, I. S. A.: Secondary organic aerosol in the global aerosol - chemical transport model Oslo CTM2, Atmos. Chem. Phys., 7, 5675-5694, 2007, http://www.atmos-chem-phys.net/7/5675/2007/.

Hoyle, C. R., Myhre, G., Berntsen, T. K., and Isaksen, I. S. A.: Anthropogenic influence on SOA and the resulting radiative forcing, Atmos. Chem. Phys. Discuss., 8, 18911-18936, 2008, http://www.atmos-chem-phys-discuss.net/8/18911/2008/. 
IPCC: The Physical Science Basis. Contribution of Working Group I to the Fourth Assessment Report of the Intergovernmental Panel on Climate Change Cambridge University Press, Cambridge, United Kingdom and New York, NY, USA, 2007.

Jacobson, M. Z.: Isolating nitrated and aromatic aerosols and nitrated aromatic gases as sources of ultraviolet light absorption, J. Geophys. Res., 104(D3), 3527-3542, 1999.

Jacobson, M. Z.: Global direct radiative forcing due to multicomponent anthropogenic and natural aerosols, J. Geophys. Res., 106(D2), 1551-1568, 2001.

Johnson, B. T., Osborne, S. R., Haywood, J. M., and Harrison, M. A. J.: Aircraft measurments of biomass burning aerosols over West Africa during DABEX, J. Geophys. Res., 113, D00C06, doi:10.1029/2007JD009451, 2008.

Johnson, B. T., Shine, K. P., and Forster, P. M.: The semi-direct aerosol effect: Impact of absorbing aerosols on marine stratocumulus, Q. J. Roy. Meteor. Soc., 130(599), 1407-1422, 2004.

Kahn, R. A., Garay, M. J., Nelson, D. L., Yau, K. K., Bull, M. A., et al.: Satellite-derived aerosol optical depth over dark water from MISR and MODIS: Comparisons with AERONET and implications for climatological studies, J. Geophys. Res., 112(D18), D18205, doi:10.1029/2006JD008175, 2007a.

Kahn, R. A., Li, W. H., Moroney, C., Diner, D. J., Martonchik, J. V., et al.: Aerosol source plume physical characteristics from spacebased multiangle imaging, J. Geophys. Res., 112(D11), D11205, doi:10.1029/2006JD007647, 2007b.

Kanakidou, M., Seinfeld, J. H., Pandis, S. N., Barnes, I., Dentener, F. J., Facchini, M. C., Van Dingenen, R., Ervens, B., Nenes, A., Nielsen, C. J., Swietlicki, E., Putaud, J. P., Balkanski, Y., Fuzzi, S., Horth, J., Moortgat, G. K., Winterhalter, R., Myhre, C. E. L., Tsigaridis, K., Vignati, E., Stephanou, E. G., and Wilson, J.: Organic aerosol and global climate modelling: a review, Atmos. Chem. Phys., 5, 1053-1123, 2005,

http://www.atmos-chem-phys.net/5/1053/2005/.

Kaufman, Y. J., Boucher, O., Tanre, D., Chin, M., Remer, L. A., et al.: Aerosol anthropogenic component estimated from satellite data, Geophys. Res. Lett., 32(17), L17804, 2005.

Kaufman, Y. J., Hobbs, P. V., Kirchhoff, V., Artaxo, P., Remer, L. A., et al.: Smoke, Clouds, and Radiation - Brazil (SCAR-B) experiment, J. Geophys. Res., 103(D24), 31783-31808, 1998.

Kaufman, Y. J., Tanre, D., and Boucher, O.: A satellite view of aerosols in the climate system, Nature, 419(6903), 215-223, 2002.

King, M. D., Kaufman, Y. J., Tanre, D., and Nakajima, T.: Remote sensing of tropospheric aerosols from space: Past, present, and future, Bull. Am. Meteor. Soc., 80(11), 2229-2259, 1999.

King, M. D., Menzel, W. P., Kaufman, Y. J., Tanre, D., Gao, B. C., et al.: Cloud and aerosol properties, precipitable water, and profiles of temperature and water vapor from MODIS, IEEE T. Geosci. Remote, 41(2), 442-458, 2003.

Kinne, S., Schulz, M., Textor, C., Guibert, S., Balkanski, Y., Bauer, S. E., Berntsen, T., Berglen, T. F., Boucher, O., Chin, M., Collins, W., Dentener, F., Diehl, T., Easter, R., Feichter, J., Fillmore, D., Ghan, S., Ginoux, P., Gong, S., Grini, A., Hendricks, J., Herzog, M., Horowitz, L., Isaksen, I., Iversen, T., Kirkevg, A., Kloster, S., Koch, D., Kristjansson, J. E., Krol, M., Lauer, A., Lamarque, J. F., Lesins, G., Liu, X., Lohmann, U., Montanaro, V., Myhre, G., Penner, J., Pitari, G., Reddy, S., Seland, O., Stier, P., Takemura, T., and Tie, X.: An AeroCom initial assessment - optical properties in aerosol component modules of global models, Atmos. Chem. Phys., 6, 1815-1834, 2006,

http://www.atmos-chem-phys.net/6/1815/2006/.

Kvalevåg, M. M. and Myhre, G.: Human impact on direct and diffuse solar radiation during the industrial era, J. Climate, 20(19), 4874-4883, 2007.

Liao, H. and Seinfeld, J. H.: Global impacts of gas-phase chemistry-aerosol interactions on direct radiative forcing by anthropogenic aerosols and ozone, J. Geophys. Res., 110, D18208, doi:10.1029/2005JD005907, 2005.

Liao, H., Seinfeld, J. H., Adams, P. J., and Mickley, L. J.: Global radiative forcing of coupled tropospheric ozone and aerosols in a unified general circulation model, J. Geophys. Res., 109(D16), D16207, doi:10.1029/2003JD004456, 2004.

Liepert, B. G.: Observed reductions of surface solar radiation at sites in the United States and worldwide from 1961 to 1990, Geophys. Res. Lett., 29(10), 1421, 2002.

Loeb, N. G. and Kato, S.: Top-of-atmosphere direct radiative effect of aerosols over the tropical oceans from the Clouds and the Earth's Radiant Energy System (CERES) satellite instrument, J. Climate, 15(12), 1474-1484, 2002.

Loeb, N. G. and Manalo-Smith, N.: Top-of-atmosphere direct radiative effect of aerosols over global oceans from merged CERES and MODIS observations, J. Climate, 18(17), 3506-3526, 2005.

Lukacs, H., Gelencser, A., Hammer, S., Puxbaum, H., Pio, C., et al.: Seasonal trends and possible sources of brown carbon based on 2-year aerosol measurements at six sites in Europe, J. Geophys. Res., 112(D23), D23S18, doi:10.1029/2006JD008151, 2007.

Magi, B. I. and Hobbs, P. V.: Effects of humidity on aerosols in Southern Africa during the biomass burning season, J. Geophys. Res., 108(D13), 2003.

Mallet, M., Roger, J. C., Despiau, S., Putaud, J. P. and Dubovik, O.: A study of the mixing state of black carbon in urban zone, J. Geophys. Res., 109(D4), D04202, doi:10.1029/2003JD003940, 2004.

Malm, W. C., Schichtel, B. A., Pitchford, M. L., Ashbaugh, L. L., and Eldred, R. A.: Spatial and monthly trends in speciated fine particle concentration in the United States, J. Geophys. Res., 109(D3), D03306, doi:10.1029/2003/JD003739, 2004.

Maria, S. F., Russell, L. M., Gilles, M. K., and Myneni, S. C. B.: Organic aerosol growth mechanisms and their climate-forcing implications, Science, 306(5703), 1921-1924, 2004.

Martin, S. T., Hung, H.-M., Park, R. J., Jacob, D. J., Spurr, R. J. D., Chance, K. V., and Chin, M.: Effects of the physical state of tropospheric ammonium-sulfate-nitrate particles on global aerosol direct radiative forcing, Atmos. Chem. Phys., 4, 183-214, 2004, http://www.atmos-chem-phys.net/4/183/2004/.

Metzger, S., Dentener, F., Pandis, S., and Lelieveld, J.: Gas/aerosol partitioning: 1. A computationally efficient model, J. Geophys. Res., 107(D16), 4312, 2002.

Morino, Y., Kondo, Y., Takegawa, N., Miyazaki, Y., Kita, K. et al.: Partitioning of $\mathrm{HNO}_{3}$ and particulate nitrate over Tokyo: Effect of vertical mixing, J. Geophys. Res., 111(D15), D15215, doi:10.1029/2005JD006887, 2006.

Myhre, G., Bellouin, N., Berglen, T. F., Berntsen, T. K., Boucher, O., et al: Comparison of the radiative properties and direct radiative effect of aerosols from a global aerosol model and remote sensing data over ocean, Tellus, 59(1), 115-129, 2007. 
Myhre, G., Berglen, T. F., Hoyle, C. R., Christopher, S. A., Coe, $\mathrm{H}$. et al.: Modelling of chemical and physical aerosol properties during the ADRIEX aerosol campaign, Q. J. Roy. Meteor. Soc., 135, 53-66, doi:10.1002/qj.350, 2009.

Myhre, G., Berntsen, T. K., Haywood, J. M., Sundet, J. K., Holben, B. N., et al.: Modeling the solar radiative impact of aerosols from biomass burning during the Southern African Regional Science Initiative (SAFARI-2000) experiment, J. Geophys. Res., 108(D13), 8501, doi:10.1029/2002JD002313, 2003a.

Myhre, G., Grini, A., Haywood, J. M., Stordal, F., Chatenet, B., et al.: Modeling the radiative impact of mineral dust during the Saharan Dust Experiment (SHADE) campaign, J. Geophys. Res., 108(D18), 8579, doi:10.1029/2002JD002566, 2003 b.

Myhre, G., Grini, A., and Metzger, S.: Modelling of nitrate and ammonium-containing aerosols in presence of sea salt, Atmos. Chem. Phys., 6, 4809-4821, 2006,

http://www.atmos-chem-phys.net/6/4809/2006/.

Myhre, G., Hoyle, C. R., Berglen, T. F., Johnson, B. T., and Haywood, J. M.: Aerosol modelling of the solar radiative impact of aerosols from biomass burning during the DABEX campaign, J. Geophys. Res., 113, D00C16, doi:10.1029/2008JD009857, 2008.

Myhre, G., Jonson, J. E., Bartnicki, J., Stordal, F., and Shine, K. P.: Role of spatial and temporal variations in the computation of radiative forcing due to sulphate aerosols: A regional study, Q. J. Roy. Meteor. Soc., 128(581), 973-989, 2002.

Myhre, G. and Stordal, F.: On the tradeoff of the solar and thermal infrared radiative impact of contrails, Geophys. Res. Lett., 28(16), 3119-3122, 2001.

Myhre, G., Stordal, F., Berglen, T. F., Sundet, J. K., and Isaksen, I. S. A.: Uncertainties in the radiative forcing due to sulfate aerosols, J. Atmos. Sci., 61(5), 485-498, 2004.

Myhre, G., Stordal, F., Johnsrud, M., Diner, D. J., Geogdzhayev, I. V., Haywood, J. M., Holben, B. N., Holzer-Popp, T., Ignatov, A., Kahn, R. A., Kaufman, Y. J., Loeb, N., Martonchik, J. V., Mishchenko, M. I., Nalli, N. R., Remer, L. A., SchroedterHomscheidt, M., Tanr, D., Torres, O., and Wang, M.: Intercomparison of satellite retrieved aerosol optical depth over ocean during the period September 1997 to December 2000, Atmos. Chem. Phys., 5, 1697-1719, 2005, http://www.atmos-chem-phys.net/5/1697/2005/.

Nakajima, T. and Higurashi, A.: A use of two-channel radiances for an aerosol characterization from space, Geophys. Res. Lett., 25(20), 3815-3818, 1998.

Ohara, T., Akimoto, H., Kurokawa, J., Horii, N., Yamaji, K., Yan, X., and Hayasaka, T.: An Asian emission inventory of anthropogenic emission sources for the period 1980-2020, Atmos. Chem. Phys., 7, 4419-4444, 2007,

http://www.atmos-chem-phys.net/7/4419/2007/.

Penner, J. E., Zhang, S. Y., and Chuang, C. C.: Soot and smoke aerosol may not warm climate, J. Geophys. Res., 108(D21), 4657, doi:10.1029/2003JD003409, 2003.

Polidori, A., Turpin, B. J., Davidson, C. I., Rodenburg, L. A., and Maimone, F.: Organic PM2.5: Fractionation by polarity, FTIR spectroscopy, and OM/OC ratio for the Pittsburgh aerosol, Aerosol Sci. Technol., 42(3), 233-246, 2008.

Putaud, J. P., Raes, F., Van Dingenen, R., Bruggemann, E., Facchini, M. C., et al.: European aerosol phenomenology-2: chemical characteristics of particulate matter at kerbside, urban, rural and background sites in Europe, Atmos. Environ., 38(16), 25792595, 2004.

Quinn, P. K. and Bates, T. S.: Regional aerosol properties: Comparisons of boundary layer measurements from ACE 1, ACE 2, aerosols99, INDOEX, ACE asia, TARFOX, and NEAQS, J. Geophys. Res., 110(D14), D14202, doi:10.1029/2004JD004755, 2005.

Ramanathan, V., Crutzen, P. J., Kiehl, J. T., and Rosenfeld, D.: Atmosphere - Aerosols, climate, and the hydrological cycle, Science, 294(5549), 2119-2124, 2001a.

Ramanathan, V., Crutzen, P. J., Lelieveld, J., Mitra, A. P., Althausen, D., et al.: Indian Ocean Experiment: An integrated analysis of the climate forcing and effects of the great Indo-Asian haze, J. Geophys. Res., 106(D22), 28371-28398, 2001 b.

Remer, L. A. and Kaufman, Y. J.: Aerosol direct radiative effect at the top of the atmosphere over cloud free ocean derived from four years of MODIS data, Atmos. Chem. Phys., 6, 237-253, 2006, http://www.atmos-chem-phys.net/6/237/2006/.

Remer, L. A., Kaufman, Y. J., Tanre, D., Mattoo, S., Chu, D. A., et al.: The MODIS aerosol algorithm, products, and validation, J. Atmos. Sci., 62(4), 947-973, 2005.

Robinson, A. L., Donahue, N. M., Shrivastava, M. K., Weitkamp, E. A., Sage, A. M., et al.: Rethinking organic aerosols: Semivolatile emissions and photochemical aging, Science, 315(5816), 12591262, 2007.

Schmid, H., Laskus, L., Abraham, H. J., Baltensperger, U., Lavanchy, V., et al.: Results of the "carbon conference" international aerosol carbon round robin test stage I, Atmos. Environ., 35(12), 2111-2121, 2001.

Schulz, M., Textor, C., Kinne, S., Balkanski, Y., Bauer, S., Berntsen, T., Berglen, T., Boucher, O., Dentener, F., Guibert, S., Isaksen, I. S. A., Iversen, T., Koch, D., Kirkevg, A., Liu, X., Montanaro, V., Myhre, G., Penner, J. E., Pitari, G., Reddy, S., Seland, ., Stier, P., and Takemura, T.: Radiative forcing by aerosols as derived from the AeroCom present-day and pre-industrial simulations, Atmos. Chem. Phys., 6, 5225-5246, 2006, http://www.atmos-chem-phys.net/6/5225/2006/.

Schwarz, J. P., Gao, R. S., Fahey, D. W., Thomson, D. S., Watts, L. A., et al.: Single-particle measurements of midlatitude black carbon and light-scattering aerosols from the boundary layer to the lower stratosphere, J. Geophys. Res., 111(D16), D16207, doi:10.1029/2006JD007076, 2006.

Stanhill, G. and Cohen, S.: Global dimming: a review of the evidence for a widespread and significant reduction in global radiation with discussion of its probable causes and possible agricultural consequences, Agr. Forest Meteorol., 107(4), 255-278, 2001.

Stier, P., Seinfeld, J. H., Kinne, S., Feichter, J., and Boucher, O.: Impact of nonabsorbing anthropogenic aerosols on clear-sky atmospheric absorption, J. Geophys. Res., 111(D18), D18201, doi:10.1029/2006JD007147, 2006.

Sun, H. L., Biedermann, L., and Bond, T. C.: Color of brown carbon: A model for ultraviolet and visible light absorption by organic carbon aerosol, Geophys. Res. Lett., 34(17), L17813, doi:10.1029/2007GL029797, 2007.

Swap, R. J., Annegarn, H. J., Suttles, J. T., King, M. D., Platnick, S., et al.: Africa burning: A thematic analysis of the Southern African Regional Science Initiative (SAFARI 2000), J. Geophys. Res., 108(D13), 8465, doi:10.1029/2003JD003747, 2003. 
Takemura, T., Nakajima, T., Dubovik, O., Holben, B. N., and Kinne, S.: Single-scattering albedo and radiative forcing of various aerosol species with a global three-dimensional model, J. Climate, 15(4), 333-352, 2002.

Textor, C., Schulz, M., Guibert, S., Kinne, S., Balkanski, Y., Bauer, S., Berntsen, T., Berglen, T., Boucher, O., Chin, M., Dentener, F., Diehl, T., Easter, R., Feichter, H., Fillmore, D., Ghan, S., Ginoux, P., Gong, S., Grini, A., Hendricks, J., Horowitz, L., Huang, P., Isaksen, I., Iversen, I., Kloster, S., Koch, D., Kirkevåg, A., Kristjansson, J. E., Krol, M., Lauer, A., Lamarque, J. F., Liu, X., Montanaro, V., Myhre, G., Penner, J., Pitari, G., Reddy, S., Seland, Ø., Stier, P., Takemura, T., and Tie, X.: Analysis and quantification of the diversities of aerosol life cycles within AeroCom, Atmos. Chem. Phys., 6, 1777-1813, 2006,

http://www.atmos-chem-phys.net/6/1777/2006/.

Turpin, B. J. and Lim, H. J.: Species contributions to $\mathrm{PM}_{2.5}$ mass concentrations: Revisiting common assumptions for estimating organic mass, Aerosol Sci. Technol., 35(1), 602-610, 2001.

van der Werf, G. R., Randerson, J. T., Giglio, L., Collatz, G. J., Kasibhatla, P. S., and Arellano Jr., A. F.: Interannual variability in global biomass burning emissions from 1997 to 2004, Atmos. Chem. Phys., 6, 3423-3441, 2006, http://www.atmos-chem-phys.net/6/3423/2006/.

Vestreng, V., Myhre, G., Fagerli, H., Reis, S., and Tarrasón, L.: Twenty-five years of continuous sulphur dioxide emission reduction in Europe, Atmos. Chem. Phys., 7, 3663-3681, 2007, http://www.atmos-chem-phys.net/7/3663/2007/.
Wentzel, M., Gorzawski, H., Naumann, K. H., Saathoff, H., and Weinbruch, S.: Transmission electron microscopical and aerosol dynamical characterization of soot aerosols, J. Aerosol Sci., 34(10), 1347-1370, 2003.

Wild, M., Gilgen, H., Roesch, A., Ohmura, A., Long, C. N., et al.: From dimming to brightening: Decadal changes in solar radiation at Earth's surface, Science, 308(5723), 847-850, 2005.

Yttri, K. E., Aas, W., Bjerke, A., Cape, J. N., Cavalli, F., Ceburnis, D., Dye, C., Emblico, L., Facchini, M. C., Forster, C., Hanssen, J. E., Hansson, H. C., Jennings, S. G., Maenhaut, W., Putaud, J. P., and Tørseth, K.: Elemental and organic carbon in $\mathrm{PM}_{10}$ : a one year measurement campaign within the European Monitoring and Evaluation Programme EMEP, Atmos. Chem. Phys., 7, 5711-5725, 2007, http://www.atmos-chem-phys.net/7/5711/2007/.

Yu, H., Kaufman, Y. J., Chin, M., Feingold, G., Remer, L. A., Anderson, T. L., Balkanski, Y., Bellouin, N., Boucher, O., Christopher, S., DeCola, P., Kahn, R., Koch, D., Loeb, N., Reddy, M. S., Schulz, M., Takemura, T., and Zhou, M.: A review of measurement-based assessments of the aerosol direct radiative effect and forcing, Atmos. Chem. Phys., 6, 613-666, 2006, http://www.atmos-chem-phys.net/6/613/2006/.

Zhang, J. L., Christopher, S. A., Remer, L. A., and Kaufman, Y. J.: Shortwave aerosol radiative forcing over cloud-free oceans from Terra: 1. Angular models for aerosols, J. Geophys. Res., 110(D10), D10S23, doi:10.1029/2004JD005009, 2005. 